Estudios Constitucionales, Año 17, No 1, 2019, pp. 321-362

ISSN 07180195

Centro de Estudios Constitucionales de Chile Universidad de Talca

"Marco constitucional de la enseñanza privada española sostenida con fondos públicos: Recorrido histórico y perspectivas a futuro" Juan José Guardia Hernández

\title{
MARCO CONSTITUCIONAL DE LA ENSEÑANZA PRIVADA ESPAÑOLA SOSTENIDA CON FONDOS PÚBLICOS: RECORRIDO HISTÓRICO Y PERSPECTIVAS A FUTURO*
}

\author{
CONSTITUTIONAL FRAMEWORK OF SPANISH PRIVATE \\ TEACHING SUSTAINED WITH PUBLIC FUNDS
}

\author{
JuAN José Guardia HeRnÁNDEZ \\ Universitat Abat Oliba CEU de Barcelona \\ jguardiah@uao.es
}

RESUMEN: El modelo constitucional educativo español actual cumplió treinta y tres años de vigencia en 2018. Uno de sus rasgos más destacables es la financiación estatal de los establecimientos docentes privados que reúnan las condiciones exigidas por la ley. El sostenimiento económico público de los centros privados constituye un ejemplo de un derecho constitucional de configuración legal. El legislador ha articulado este derecho a través de un sistema de conciertos educativos que suscita muchos interrogantes, sobre todo por su otorgamiento restrictivo, al estar supeditado a la planificación educativa estatal. En el fondo de la controversia constitucional subyace la calificación de la educación como un servicio público o como un servicio de interés público.

ABSTRACT: The current Spanish constitutional educational model is Thirty-three years old in 2018. One of its most outstanding features is the state funding of private educational establishments that meet the conditions required by Law. The public economic sustainability of private schools is an example of a legally-based constitutional right. The legislation articulates this right through a system of educational agreements that raises many questions, especially as regards its restrictive granting, being subject to State educational planning. At the bottom of the constitutional controversy lies the definition of education as a public service or a service of public interest.

PALABRAS CLAVE: Libertad de enseñanza, educación pública, colegios concertados, bonos escolares, libertad de elección de centro docente.

KEY WORDS: Freedom of education, public education, charters schools, vouchers, choice of school.

\footnotetext{
* Trabajo recibido el 1 de junio de 2018 y aprobado el 8 de mayo de 2019.

** Licenciado en Derecho por la Universidad de Navarra y doctor en Derecho por la Universitat de Barcelona. Profesor adjunto de la Universitat Abat Oliba CEU de Barcelona. Este artículo deriva del proyecto DER2015-65223-C3-1-R, «El Estado garante. Un nuevo modelo para afrontar los presentes retos sociales y económicos del Estado de bienestar», financiado por el Ministerio de Economía y Competitividad de España, BOE No 149, de 23.06.2015.
} 


\section{INTRODUCCIÓN}

El marco constitucional de los derechos educativos ha sido a lo largo de la democracia española un campo abonado para el debate y la controversia. Buena prueba de ello han sido las sucesivas leyes que en este ámbito se han sucedido, la movilización social que han generado y la conflictividad jurisdiccional que ha producido su aplicación por las distintas administraciones educativas ${ }^{1}$.

El sistema actual tiene su origen en el art. 27 de la vigente Constitución española de 1978 (en adelante, CE) y en su desarrollo legal realizado en 1985, por la Ley Orgánica No 8/1985, de 3 de julio, reguladora del derecho a la educación (en adelante, LODE). Es decir, en el año 2019 el modelo actual cumple exactamente 34 años de vigencia.

El tiempo transcurrido invita a realizar un análisis retrospectivo desde la perspectiva constitucional sobre su impacto en el derecho a la educación y en la libertad de enseñanza, tanto en su dimensión de libertad como en su dimensión prestacional. En ese sentido, será necesario hacer especial referencia al último capítulo de la guerra escolar ${ }^{2}$, si se puede denominar de esta manera, constituido por la Ley Orgánica No 8/2013, de 9 de diciembre, para la mejora de la calidad educativa (en adelante, Lomce) ${ }^{3}$. Esta norma -aun no implantada en la actualidad en toda su extensión ${ }^{4}$ - no modifica el nervio de la regulación existente, vigente

1 Cfr. Nuevo (2014), p. 208. El art. 2º bis de la Ley Orgánica No 2/2006, de 3 de mayo, de Educación, identifica como "Administraciones educativas" a los órganos de la Administración General del Estado y de las Administraciones de las Comunidades Autónomas competentes en materia educativa. Por lo tanto, se excluye de este concepto a las municipalidades y resto de entes locales. Bajo el sintagma "Administración General del Estado" se debe entender el conjunto de entes que, bajo la dirección del gobierno de España, desarrollan e implementan sus políticas públicas o prestación servicios. Bajo la expresión "Administraciones de las Comunidades Autónomas", de modo análogo, se debe entender los entes públicos al servicio de los gobiernos de cada una de las 17 comunidades autónomas en que está dividida España.

2 Tomo esta expresión de Martínez López-Muñiz (2004), p. 32, y de Díez-Picazo (2008), p. 495. También se usa "guerra educativa» en NuEVo (2009), p. 151.

3 A diferencia de ocasiones anteriores análogas, no se trató de una norma que procedía a la supresión de la precedente ley de educación, sino que formalmente constituyó una modificación de la Ley Orgánica No 2/2006, de 3 de mayo, de educación (LOE).

${ }^{4}$ Los condicionamientos políticos acaecidos en España tras la promulgación de la Lomce en el año 2013 han impedido que despliegue toda su eficacia. En el año 2016 las fuerzas políticas pactaron una moratoria de algunos aspectos de la Lomce. Para esta finalidad, el anterior ejecutivo español aprobó el Real Decreto Ley No 5/2016, de 9 de diciembre, de medidas urgentes para la ampliación del calendario de implantación de la Ley Orgánica No 8/2013, de 9 de diciembre, para la mejora de la calidad educativa. El 1 de junio de 2018 una moción de censura cesa a Mariano Rajoy Brey como presidente del gobierno, que es sustituido 
desde $1985^{5}$, pero introduce algunos elementos nuevos que inducen a pensar que habrá más cambios en el futuro, quizás de la mano de nuevas resoluciones judiciales, favorables a facilitar la elección de las madres y los padres del centro docente para sus hijos.

Como quiera que sea, a modo de introducción, es necesario advertir que la redacción del citado art. $27 \mathrm{CE}$ es confusa. Se usan los conceptos "educación” y "enseñanza" indistintamente con diferente significado dentro del propio artículo6. Podríamos decir, para clarificar los términos, que la ley fundamental reconoce una serie de derechos y libertades que en su conjunto constituyen los denominados "derechos educativos". Simultáneamente, se instauran unos principios informadores de la actividad de los poderes públicos de los que, a su vez, se derivan otros derechos o títulos de intervención de la administración educativa.

La configuración constitucional de los derechos educativos en España, circunscribiéndonos exclusivamente a la enseñanza no universitaria, pivota sobre estas dos categorías: derechos y libertades, por un lado, y principios informadores del sistema educativo, por otro. Siguiendo a Vidal, entendemos que ${ }^{7}$ :

Bajo la categoría de derechos y libertades encontramos el derecho a la educación en sentido estricto (art. 27.1 CE), esto es, el derecho a recibir instrucción por quien carece de ella. El discente, o sus representantes legales, se encuentra en una posición jurídica activa frente a los poderes públicos, de modo que puede exigir que se le preste ese servicio. También habría que incluir en esta categoría a la libertad de enseñanza, que contiene el derecho a la creación de centros docentes (art. 27.6 CE) y dotarlos de ideario propio; el derecho a recibir formación religiosa y moral acorde a las propias convicciones (art. 27.3 CE); el derecho es escoger centro docente, estatal o no, y, por último, la libertad de catedra (art. 20.1 c), CE) 8 .

por Pedro Sánchez Pérez-Castejón. Este último gana las elecciones generales de abril de 2019 y ha prometido una revisión del sistema de conciertos.

5 Cfr. Vidal (2017), pp. 11-12.

6 Ibídem, pp. 18-19.

7 Cfr. ibídem, pp. 17-26.

8 Como se observa, algunos aspectos de los derechos educativos se encuentran en preceptos constitucionales distintos al art. $27 \mathrm{CE}$, como es el caso de la libertad de cátedra, que se encuentra en el art. $20 \mathrm{CE}$. El constituyente por razones sistemáticas quiso enumerar este último derecho en el marco de los derechos de la comunicación, como son la libertad de prensa y de creación literaria, artística, científica y técnica. 
Bajo la categoría de los principios informadores se encuentra el principio de constitucionalidad de las enseñanzas impartidas en España (art. 27. 2, CE) que implica el respeto en los centros estatales de la pluralidad ideológica y religiosa, y en los centros no estatales con ideario propio -reciban o no financiación pública- el respeto al marco constitucional ${ }^{9}$. También hay que aludir al principio de obligatoriedad y gratuidad de la enseñanza básica (art. 27.4 CE) y al principio de participación en el control y gestión por parte de padres y alumnos en los centros sostenidos con fondos públicos (art. 27.7 CE). Este último exige la existencia de órganos de gobierno en los establecimientos docentes en los que participe toda la comunidad educativa, es decir, padres, profesores y alumnos. Hay que incluir, por otra parte, el principio de intervención pública en el sistema educativo, que conlleva la creación estatal de centros docentes (art. 27.5 CE), la programación general estatal de la enseñanza (art. 27.5 CE), la inspección y homologación de todo el sistema educativo (art. 27.8 CE) y financiación pública a los centros docentes no estatales que cumplan los requisitos legales (art. 27.9 CE).

Esta enumeración sería incompleta si no aludiésemos a la transformación de Estado unitario a Estado compuesto que se produce en España desde la CE. En efecto, se puede afirmar que el sistema educativo español está informado por otro principio que podríamos denominar como de corresponsabilidad del Estado central y de las comunidades autónomas en el sistema educativo, dada la gran descentralización política que existe en España ${ }^{10}$. Analizaremos este último aspecto con cierto detalle, como se verá.

Dados estos imprescindibles antecedentes constitucionales, ahora sí estamos en condiciones de definir exactamente cuál es el objeto de este trabajo: nuestra intención es abordar y analizar, con carácter crítico, el actual modelo constitucional español relativo a la financiación con fondos públicos de la enseñanza privada derivado directamente del art. 27.9 CE. Todo ello sin perjuicio de que hay otras muchas polémicas constitucionales en esta materia, como se intuye con la somera descripción del contenido de los derechos y principios educativos en

\footnotetext{
9 Es decir, el carácter propio o ideario de un centro docente no estatal no ampara las enseñanzas que fomenten el odio racial, religioso o ideológico, ni la promoción o justificación de grupos terroristas o xenófobos: Díez-PicAzo (2008), pp. 497-498. Véase también SSTC 5/1981 y 77/1985.

10 Algunos autores prefieren denominarlo principio de compartición estatal entre Estado central y comunidades autónomas en el sistema educativo: cfr. VIDAL (2017), p. 22. Sobre esta cuestión, cfr. MeIX (2013). Para una panorámica general del régimen de competencias y relaciones entre el Estado y las comunidades autónomas: CASTELlà (2014), pp. 375-392.
} 
la ley fundamental española que hemos realizado con precedencia. No es posible ahora un análisis profundo de todos y cada uno de estos aspectos, pues exceden con mucho del ámbito material posible de este trabajo.

Por lo tanto, para una investigación del marco constitucional de la enseñanza privada española sostenida con fondos públicos, a continuación vamos a examinar en primer lugar la controvertida naturaleza constitucional de esa financiación pública (epígrafe I). Tras este estudio, se analiza el concierto educativo, es decir, el concreto sistema técnico que el legislador español ha previsto para financiar a algunos centros docentes no estatales (epígrafe II). En este punto, nos detendremos en sus antecedentes y, en especial, en el acceso a este sistema, todo ello para evaluar hasta qué punto responden al diseño constitucional. Este trabajo finalizará con algunas conclusiones críticas a la génesis del actual modelo educativo español y al desarrollo del art. $27 \mathrm{CE}$ realizado parlamentariamente.

Se requiere, sin embargo, una última precisión terminológica. En este trabajo designaremos como enseñanza estatal o educación pública al conjunto de establecimientos docentes de titularidad de algún poder público. Estos centros de enseñanza forman parte de la administración pública, su personal está constituido por empleados públicos, y su régimen jurídico es estrictamente el propio del derecho administrativo, dependiendo jerárquicamente de una administración.

En ese sentido, por el contrario, denominaremos enseñanza no estatal, educación privada o centros de iniciativa social, a los establecimientos docentes pertenecientes a personas físicas o jurídicas privadas ${ }^{11}$, todo ello con independencia de que reciban o no financiación pública. Estos centros educativos no son propiedad de ningún poder público, tienen autonomía, y sus decisiones de gobierno, con carácter general, no deben someterse a la aprobación de ninguna administración ${ }^{12}$.

\section{NATURALEZA CONSTITUCIONAL DE LA FINANCIACIÓN PÚBLICA DE LA ENSEŃANZA PRIVADA}

El estatuto constitucional de la libertad de enseñanza en España tiene como punto de partida, como ya hemos adelantado, el art. $27 \mathrm{CE}$. Es, probablemente,

\footnotetext{
11 Sigo en parte la terminología propuesta por Martínez López-Muñiz (2007), pp. 24-25.

12 La financiación pública no produce la propietarización estatal del establecimiento educativo. Tampoco existe en España un sistema mixto o mancomunado de propiedad educativa. En todo caso, los establecimientos privados sostenidos con fondos públicos mantienen su independencia en la gestión y gobierno, aunque tienen algunas limitaciones a su autonomía como contraprestación a los caudales públicos que reciben, tales como la prohibición de la selección del alumnado.
} 
uno de los artículos más polémicos en las Cortes Constituyentes ${ }^{13}$. Este precepto afirma, entre otros aspectos, que "se reconoce la libertad de enseñanza" y que "se reconoce a las personas físicas y jurídicas la libertad de creación de centros docentes”. A los efectos de este estudio es relevante el último inciso, que señala: "Los poderes públicos ayudarán a los centros docentes que reúnan los requisitos que la ley establezca".

La primera tarea que se impone al intérprete de la Carta Magna es precisar la naturaleza del mandato contenido en el citado art. 27.9 de la CE ("ayudarán a los centros docentes") ${ }^{14}$, pues el tiempo verbal empleado ("ayudarán”) sugiere que no estamos ante una mera posibilidad al albur del legislador. En otras palabras, dada la literalidad del artículo parece que, si no se arbitrase algún sistema para articular este mandato, se estaría incumpliendo la Carta Magna.

Ahora bien, el constituyente no estableció para las generaciones futuras un modelo acabado y cerrado de cómo debía el legislador cumplir este mandato. Es probable que sean posibles en España varios modelos, muy dispares entre ellos, y todos ellos constitucionales. En otras palabras, el que finalmente decantó, y que se estudia en el epígrafe II, no es el único constitucionalmente posible, por más que tenga más de 30 años de antigüedad.

A continuación, estudiaremos dos cuestiones. A nuestro juicio es necesario dilucidar si la CE entiende que el mandato del art. 27.9 constituye un derecho de libertad o, por el contrario, constituye un derecho de prestación (subepígrafe I.1). Adelantamos que nuestra posición es que se trata de una prestación pública a favor de la iniciativa social educativa, lo que nos suscita otro interrogante, pues ello implica que hay que esclarecer si este derecho deriva directamente de la misma Constitución o, por el contrario, es necesario un desarrollo legal que regule y determine cuándo y cómo se puede solicitar por parte de los ciudadanos (subepígrafe I.2). Esta cuestión es de especial relevancia, pues puede supeditar el expeditivo mandato del art. 27.9 CE al desarrollo parlamentario y, en su caso, también reglamentario.

13 Cfr. Martínez López-Muñiz (2006a), pp. 793-816: "El establecimiento de las bases constitucionales del sistema educativo figuró entre los puntos más difíciles e importantes del consenso político que hizo posible la Constitución. Momentos hubo, en el proceso constituyente, en que todo estuvo a punto de atascarse precisamente por causa de esta relevante cuestión”. También: Nuevo (2014), p. 207; Cotino (2014), pp. 415-416.

${ }^{14}$ La literalidad de este artículo («ayudarán») invita considerar que estamos ante un auténtico mandato constitucional. Otra cosa es que se deba dilucidar si estamos antes una regla jurídica o más bien ante un principio, es decir, un mandato de optimización: Nuevo (2009), pp. 104-105. 


\section{I.1. Derecho de LiberTad o Derecho De PRESTACión}

En efecto, como es conocido, la doctrina constitucionalista clásica suele distinguir por su naturaleza dos tipos de derechos fundamentales: derechos de libertad y derechos de prestación. Los primeros constituyen una delimitación negativa "del ámbito de actuación del individuo; ello significa que, en cuanto límite, lo que imponen básicamente es una actitud de abstención por parte, en especial del poder público" 15 .

Los segundos, esto es, los derechos de prestación, sin embargo, sí requieren una actitud activa de los poderes públicos, lo que puede implicar, en su caso, el destino de fondos públicos para que ese derecho fundamental pueda ser ejercitado por los ciudadanos.

Con estos términos de debate, y con la confusa redacción del art. 27 CE, podemos intentar derivar qué es lo que los constituyentes determinaron para España en el año 1978. En otras palabras, si en ese país la Carta Magna califica la libertad de enseñanza como un derecho de libertad o como un derecho de prestación, con todas las consecuencias que de ello se derivan.

En el primer caso, se entendería que no es necesaria una financiación pública de la enseñanza distinta a la oferta educativa estatal. Las obligaciones de la administración educativa con respecto a esta libertad se limitarían a permitir la existencia de centros docentes privados o de la iniciativa social, sin comprometer gasto público alguno.

A modo de ejemplo, Satrustegui afirma que "La libertad de creación de centros [de enseñanza] no entraña un derecho constitucional a la subvención (...). Dicho de otro modo, no hay un deber constitucional de subvencionar a todos los centros privados, por el mero hecho de serlo16". Este autor defiende que el derecho a escoger el tipo de educación "es exclusivamente un derecho de libertad (la de optar por una oferta educativa privada) y no puede dar cobertura a la exigencia de subvenciones de los poderes públicos para el centro elegido por los padres, ni

15 Cfr. Pérez (2013), p. 128. No obstante esta distinción dogmática, en la realidad muchas veces no se puede disociar ambos tipos de derechos con tanta claridad. Ver también Díez-Picazo (2008), pp. 107108: "Los derechos fundamentales no se configuran únicamente como derechos de defensa, que quedan satisfechos mediante una mera abstención por parte de los poderes públicos (libertad personal, libertad de expresión, intimidad). Hay también derechos fundamentales que otorgan pretensiones de participación (sufragio, acceso a las funciones públicas), de percepción de utilidades colectivas (tutela judicial efectiva) o de prestación en sentido propio (educación)".

16 Satrustegui (2013), p. 357. 
faculta a los padres para exigir que sus hijos reciban la enseñanza en los centros públicos, conforme a un determinada orientación ideológica o religiosa o en la lengua de sus preferencias" 17.

Ahora bien, si se entiende que la libertad de enseñanza se incluía entre los derechos de prestación -este es el segundo caso-, la financiación pública de la enseñanza no estatal se convierte en garantía de la existencia de una oferta educativa plural, y en la posibilidad real de que los padres pudiesen elegir en libertad en qué centro docente deseaban escolarizar a sus hijos, sin que los recursos económicos limitasen sus opciones.

En nuestra opinión, de la dicción literal del art. 27.9 CE se sigue la asunción constitucional de la existencia de un pluralismo escolar. Y, a contrario sensu, la proscripción de un monopolio de cualquier índole o naturaleza de esta activi$\mathrm{dad}^{18}$. Por todo ello corresponde a los poderes públicos establecer un modelo educativo en el que quede garantizada esta libertad. Ciertamente, en la medida de las competencias que a cada nivel institucional le corresponda ${ }^{19}$.

Por lo tanto, la CE no estableció con respecto a la iniciativa social en materia educativa un mero estatuto laissez faire, laissez passer, sino que preveía la cooperación económica con la enseñanza privada. Por esta razón, algún autor viene a afirmar que en este ámbito debe existir una cierta actividad de fomento administrativo con los centros de iniciativa social ${ }^{20}$.

De lo que se deduce, en buena lógica, que la CE no entiende la libertad de enseñanza como una mera libertad individual, que es satisfecha con la sola abstención del Estado y la oferta de plazas escolares públicas. No se limita a crear una prohibición de prohibir ${ }^{21}$. Con todo, esta conclusión lleva a otra controversia

17 Ibídem, p. 358.

18 Cfr. Еmbid (1997), pp. 75-102.

19 Sobre la pérdida de las competencias educativas de las municipalidades, cfr. TARDío (2014), pp. 113-135.

20 Empleo la locución "actividad de fomento" en el sentido iusadministrativo estricto que es de uso común en la doctrina española: EsTEVE (2017), pp. 355-356 y 415-416. Esta actividad de fomento es una modalidad de intervención pública consistente en dirigir la acción de los particulares hacia fines de interés general mediante el otorgamiento de incentivos diversos. Se distingue de la actividad administrativa de policía y de la actividad administrativa de servicio público (o actividad de prestación).

21 En contra de nuestra opinión, se puede citar a FernÁNdeZ y MuñIz (2012), p. 98. Para estos autores, la financiación pública de la enseñanza privada tuvo justificación, en un primer momento, "como complemento a una red pública que no era capaz de atender una creciente demanda de plazas escolares, sobre todo, por dos motivos: el fuerte crecimiento demográfico (baby boom) y la ampliación de los años de escolarización obligatoria". Desaparecidas esas circunstancias sociales, afirman que es "cuestionable la figura del centro 
constitucional relativa al ejercicio de este derecho, cuestión que trato con detalle a continuación.

\section{I.2. El DERECHO A ACCEDER A FINANCIACIÓN PÚBLICA, ¿ES UN DERECHO DE CONFIGURACIÓN LEGAL?}

En efecto, la libertad de enseñanza, como hemos señalado, puede ser considerada como un derecho de prestación. Ahora bien, cuestión distinta es si el derecho a acceder al sostenimiento económico público (el denominado "concierto económico", como veremos) trae causa directamente de la propia Constitución dada la eficacia directa y normativa de la ley fundamental, o es necesaria una ley que regule y establezca cómo y con qué condiciones se puede obtener la referida financiación estatal.

En otras palabras, si existe en España un derecho inmediatamente derivado de la Constitución a beneficiarse de fondos públicos para proveer enseñanza en niveles obligatorios en centros distintos de los estatales, es decir, una suerte de derecho subjetivo constitucional. $\mathrm{O}$ es un derecho mediato que requiere un desarrollo legal, sin el cual no puede ejercitarse, y que permite al legislador español introducir condiciones o límites para su ejercicio y, por tanto, siguiendo esta lógica, pueden ser necesarios reglamentos de ejecución de esas leyes orgánicas ${ }^{22}$. Para dilucidar estas cuestiones, a nuestro juicio, es necesario remontarse al pacto constitucional de 1978, es decir, al momento genético de la vigente ley fundamental. Las evidencias que resulten nos permitían emitir un juicio constitucional al respecto y también algunas propuestas en las conclusiones de este trabajo.

El acceso por parte de los centros docentes privados a la financiación pública estuvo -como hemos adelantado- muy presente en los debates constituyentes,

concertado tal y como se concibió en sus orígenes". No entienden ese sostenimiento financiero estatal como una plasmación práctica de un mandato constitucional -que constituye la tesis dominante en la doctrina española-, sino como una solución transitoria hacia una provisión estatal mayoritaria de la educación.

22 De conformidad con el art. $81 \mathrm{CE}$, se consideran leyes orgánicas aquellas relativas al desarrollo de los derechos fundamentales y de las libertades públicas, las que aprueben los Estatutos de Autonomía y el régimen electoral general. En otros preceptos de la Constitución se atribuyen a otros supuestos la necesidad de su regulación mediante este tipo de leyes, como por ejemplo las normas reguladoras de los órganos constitucionales (o de relevancia constitucional), el ejercicio de determinados derechos o la configuración del denominado Estado autonómico. Su nota más característica es que su aprobación, modificación o derogación exigirá mayoría absoluta, no mayoría simple, del Congreso, es decir de la Cámara baja, en una votación final sobre el conjunto del proyecto. 
en concreto en la redacción de art. 27.9 CE23. Este último artículo establecía, en una primera redacción, que "Los poderes públicos ayudarán a los centros docentes". Los detractores de esta versión inicial del artículo condicionaron su apoyo a la introducción de una enmienda con la siguiente cláusula: "que reúnan los requisitos que la Ley establezca" 24 , enmienda que fue aprobada e incorporada al texto constitucional. Esta redacción es un ejemplo de los equilibrios que fue necesario alcanzar para conseguir una ley fundamental aceptable por todos, pero que legó un artículo con cierto grado de indefinición y de ambigüedad ${ }^{25}$. En efecto, se permite a las diferentes mayorías parlamentarias configurar el sostenimiento económico público de los centros docentes privados con mayor o menor amplitud; es decir, que las posibilidades reales de libre elección de centros docentes por los padres quedan muy supeditadas a lo que se establezca legislativamente. A nuestro juicio, este margen de discrecionalidad con respecto a este aspecto de la libertad de enseñanza fue el precio constitucional a pagar por alcanzar el deseado consenso y reconciliación nacional, y que prolonga en el tiempo, como ya hemos mencionado, una "guerra escolar". Desde el punto de vista constitucional, esto provoca que no se haya alcanzado nunca un gran pacto de Estado en materia escolar y todo quede al albur de las coyunturales mayorías parlamentarias.

Estas consideraciones permiten, al menos, dos interpretaciones constitucionales del art 27.9 de la Ley Fundamental: una primera que afirma que sí existe un derecho fundamental al acceso a la financiación pública, manifestación del principio de subsidiariedad ${ }^{26}$, y una segunda que opina que en realidad estamos ante un claro derecho de configuración legal ${ }^{27}$.

En esta controversia, el primer legislador español tras la CE (1979-1982) pretendió implementar unas ayudas económicas a cada familia cuyo destinatario final sería el centro docente elegido por los padres o tutores legales. De alguna

23 En este sentido, cfr. GARRIDO (2003), p. 234. El art. 27 CE “cubre en realidad tres problemas clásicos de nuestra historia constitucional: la confesionalidad del Estado, la antítesis clericalismo-anticlericalismo y la oposición enseñanza laica-enseñanza religiosa".

24 Cfr. Prieto (1978), pp. 319-376.

25 Sobre la reconciliación nacional, cfr. ÁLVAREZ (2005).

26 Denominado, a veces, como un derecho público subjetivo constitucional debilitado: cfr. De Los Mozos (1996), p. 108, nota 183.

27 Cfr. Fernández-Miranda (2006), p. 60: "no existe un derecho subjetivo constitucional de los colegios privados a la financiación pública, ni tal derecho puede deducirse, según creo, de la gratuidad y la obligatoriedad de la educación. Lo que sí existe es una obligación de los poderes públicos de financiar a los centros privados en el marco que establezca la ley". 
manera, este sistema podría avalar la tesis de que estábamos ante un derecho público subjetivo derivado directamente de la propia Constitución. Ahora bien, esta no es la solución que se impuso. Es crucial, pues, la opción elegida en el año 1985 por el Parlamento de la segunda legislatura de la democracia en la Ley Orgánica del Derecho a la Educación (LODE). Se prefirió decididamente la segunda respuesta. Es decir, sí existe una obligación de los poderes públicos de financiar a los centros privados en el marco, con las condiciones y los términos establecidos por la ley. Luego, no es un derecho público subjetivo exigible sin mediación de norma legal alguna.

En otras palabras, se arbitra en la LODE, efectivamente, un sistema de financiación a los centros de la iniciativa social (los denominados conciertos educativos), pero su exigibilidad queda supeditada al régimen y a la planificación educativa de los poderes públicos. Por lo tanto, no se consideró como un derecho fundamental, directamente exigible ex constitutione, sino solo en la medida en que haya sido reconocido en los textos legales de desarrollo. Por consiguiente, en técnica constitucional: un derecho de configuración legal.

Es oportuno señalar que esta categoría ha sido usada por el TC español ${ }^{28}$ para designar a auténticos derechos fundamentales, no meros derechos creados por el legislador. Es decir, derechos reconocidos en la Ley Fundamental, pero que están necesitados "de un complemento legislativo que termine de diseñar su contenido $y$, por consiguiente, les permita alcanzar plena efectividad 29 ".

Parece que, pues, la referencia constitucional del art. 27.9 in fine a "los requisitos que señalen las leyes” es coherente. Este añadido al referido artículo avala un "amplio margen de apreciación al legislador a la hora de diseñar sus ayudas a centros educativos privados" 30 . De todo ello se hizo eco el TC cuando se vio obligado a pronunciarse a respecto, como ahora veremos.

Como era de esperar, la LODE de 1985 fue impugnada ante el Tribunal Constitucional. Y se invocó, precisamente, que se contravenía el citado art. 27.9 de la CE. El Tribunal de Garantías no acogió la tesis de los recurrentes y confirmó la interpretación que había hecho el legislador de 1985. En efecto, las controvertidas sentencias 77/1985, de 27 junio, y 86/1985, de 10 de julio, afirmaron que del mencionado art. 27.9 CE no se desprende un derecho fundamental incon-

28 Cfr. SSTC 23/1982, 30/1985, 15/1990, entre otras.

29 Díez-Picazo (2008), pp. 126-127.

30 Ibídem, p. 503. 
dicionado a una prestación económica pública a favor de centros privados y -lo que es más importante- que del derecho fundamental a una educación gratuita en la enseñanza obligatoria no se deriva "el derecho a la gratuidad educativa en cualesquiera centros privados, porque los recursos educativos no han de acudir, incondicionalmente, allí donde vayan las preferencias individuales"31. En otras palabras, se afirma que la Carta Magna realiza una remisión al legislador para que dé contenido a lo establecido en el art. 27.9 CE, de modo que, en realidad, el derecho a la financiación no surge directamente de la Constitución, sino de la ley ${ }^{32}$. Se advierte rápidamente que el abanico de posibilidades que se deja en manos del legislador español y de su ejecución por las administraciones educativas es muy amplio. A la postre, en nuestra opinión, la jurisprudencia constitucional ha avalado que el Parlamento español pueda aprobar una legislación más propicia o más contraria a la libertad de elección de centro educativo, en función de los intereses de los partidos políticos con mayoría en las cámaras legislativas nacionales.

\section{Marco Constitucional y Legal DeL}

\section{RÉGIMEN DE CONCIERTOS EDUCATIVOS}

Ahora bien, con independencia del debate dogmático descrito, ¿̨uál ha sido el desarrollo legal del mandato contenido en el art. 27.9 CE? Esto es, del mandato dirigido a los poderes públicos para que estos ayuden "a los centros docentes que reúnan los requisitos que la ley establezca”. Como hemos adelantado en el epígrafe I, el constituyente español no estableció un modelo acabado y cerrado de cómo debía el legislador cumplir este mandato. En síntesis, el legislador español ha dado dos soluciones. Un primera, efímera y que no llegó a implantarse -como hemos adelantado-, que pretendía financiar la demanda educativa, es decir, a las

31 El mismo argumento aparece en la STC 195/1989, de 27 de noviembre, para la pretensión de un particular de que se le abonasen los gastos de transporte y comedor escolar a que se veía obligado por estar situado el colegio en el que sigue estudios su hijo lejos del domicilio familiar, y ser este el único centro de la ciudad en el que toda la enseñanza se impartía en valenciano.

32 La mencionada STC 86/85, de 10 de julio, afirma que "el citado art. 27.9, en su condición de mandato al legislador, no encierra, sin embargo, un derecho subjetivo a la prestación pública”. El alto tribunal matiza que, sin embargo, ello no significa que "el legislador sea enteramente libre para habilitar de cualquier modo este necesario marco normativo", sino que el desarrollo legal del art. 27.9 CE respetará los derechos y libertades educativas presentes en este artículo y, en todo caso, "deberá configurar el régimen de ayudas en régimen de igualdad". 
familias. Y una segunda que, finalmente, es la que se ha establecido y perdura hasta la fecha, y que financia la oferta educativa, esto es, a los centros docentes.

La primera plasmación del art. 27.9 CE se suele denominar en España cheque escolar ${ }^{33}$. Iba a ser la solución del gobierno de Adolfo Suárez González en la I Legislatura (1979-1982) 34 ; sin embargo, las adversas circunstancias políticas impidieron llevarla a la práctica. Se trata de una financiación económica que se transfiere directamente a las familias, de forma que estas son las que deciden el centro educativo al que envían a sus hijos. La cantidad transferida por cada alumno escolarizado se corresponde con el coste del puesto escolar. Es una técnica que quiere introducir competencia entre los centros escolares para incentivar una mejora educativa.

Lo cierto es que el desarrollo definitivo de la constitución educativa fue realizado con posterioridad por el gobierno de Felipe González Márquez ${ }^{35}$ (II Legislatura, 1982-1986), y se articuló de una manera muy distinta. En este segundo modelo, el eje de la configuración legal de la libertad de enseñanza pivota en la financiación de la oferta, esto es, los colegios. La técnica jurídica empleada para el sostenimiento de los establecimientos docentes privados se denominó concierto escolar.

A continuación, expondré el origen de la técnica del concierto (subepígrafe II.1) y las dificultades del acceso a este (subepígrafe II.2).

\section{II.1. EL CONCIERTO ECONÓMICO ESCOLAR: ANTECEDENTES}

El concierto no es un instrumento jurídico original. Podemos encontrar un doble antecedente. En cuanto al derecho comparado, constituye la versión española de la francesa ley Debré, de 31 de diciembre de 195936. En cuanto al derecho

33 Este mecanismo es conocido también como vouchers o bonos. Esta técnica aplicada al ámbito educativo fue propuesta por primera vez en Friedman (1955), pp. 123-144. Sobre el cheque escolar en España, cfr. MARTÍNEZ (2004), pp. 293-315.

34 Para ser precisos, Adolfo Suárez González presentó su dimisión el 29 de enero de 1981 y las Cámaras eligieron a Leopoldo Calvo-Sotelo como nuevo presidente el 25 de febrero de ese año. Este gobierno fue muy efímero, pues la II Legislatura (1982-1986), con Felipe González Márquez, dio comienzo el 18 de noviembre de 1982.

35 Partido Socialista Obrero Español (PSOE).

36 Loi No 59-1557 du 31 décembre 1959 sur les rapports entre l'État et les établissements d'enseignement privés. Michel Debré (1912-1996): contribuyó a la redacción de la Constitución de la V República Francesa (1958 hasta la fecha). Colaborador de Charles de Gaulle, fue primer ministro desde enero de 1959 hasta 
interno, una figura análoga al concierto se intentó implementar en España al final del régimen del general Franco, aunque los avatares políticos impidieron que aquella reforma prosperara ${ }^{37}$.

Así pues, la LODE (1985) constituyó el segundo intento de importar a España el sistema de sostenimiento económico de la educación privada establecido por De Gaulle en 1959. En esta ocasión, la reforma sí se generalizó. Se puede decir que esta norma pudo ser aprobada y permanecer en el tiempo por la cómoda mayoría absoluta del partido en el gobierno en las cámaras legislativas en 1985 y en sucesivas legislaturas. Todo ello sin tener que pactar con ninguna fuerza política ningún extremo de la LODE, o tener que ceder en algún aspecto.

En resumidas cuentas, se podría afirmar que el legislador español de 1985 distinguió dos tipos de establecimientos educativos. Los centros privados que funcionan en régimen de mercado, mediante precio, con libertad para determinar el procedimiento de admisión de alumnos, y los denominados centros sostenidos con fondos públicos. Entre estos últimos, además, hay que distinguir entre los privados concertados y los de titularidad de alguna administración pública. Estos establecimientos financiados con fondos públicos necesariamente deben ser gratuitos y no seleccionar a sus alumnos. Hay que añadir que la financiación pública no elimina la posibilidad de que los centros docentes concertados puedan tener un ideario o carácter propio, definido por la persona física o jurídica (sostenedor) que ostente la titularidad del establecimiento ${ }^{38}$.

\section{II.2. El DERECHO AL ACCESO AL CONCIERTO ECONÓMICO}

El sistema español es restrictivo con respecto a las peticiones de los centros educativos privados que desean ser acogidos al régimen de concierto ${ }^{39}$. Como

abril de 1962. La ley de educación que lleva su nombre fue promulgada durante el desempeño de esta alta magistratura. Esencialmente esta norma -pese al transcurso de más de 50 años- sigue vigente, incluida en Code de l'éducation desde el año 2000.

37 En concreto, me estoy refiriendo a la Ley General de Educación de 1970, que no pudo ser implantada por el ocaso, entonces inminente, del régimen franquista (1939-1975).

38 El Tribunal Constitucional español avaló en sus primeras sentencias a los colegios concertados con ideario propio. En la STC 5/1981, de 13 de febrero, se precisó, además, que "El derecho a establecer un ideario no está limitado a los aspectos religiosos y morales de la actividad educativa”.

39 La naturaleza jurídica del concierto es discutida en la doctrina. Para una parte de ella, se trata de una subvención pública; por ejemplo, Díaz (1992), pp. 159-162. Para otro sector se trata más bien de un contrato 
hemos adelantado, la Constitución y la legislación de desarrollo deja un amplio margen de discrecionalidad administrativa que es de muy difícil control judicial.

Analizamos a continuación (subepígrafe II.2.1) la política pública generalizada y el fundamento legal que la sustenta. Después (subepígrafe II.2.2) realizaremos algunas consideraciones críticas desde la perspectiva constitucional. Creemos que resulta imprescindible también indagar en cómo se implementó el acceso al concierto económico en los distintos territorios que componen España, es decir, en las distintas comunidades autónomas, cosa que nos ocupará en el subepígrafe II.2.3.

\section{II.2.1. La denegación del concierto económico: La planificación educativa}

La praxis administrativa habitual en la mayoría de las comunidades autónomas (en adelante también CC. AA.) ha sido denegar las peticiones de conciertos económicos si en el ámbito territorial del centro educativo peticionario existían plazas libres en los colegios estatales. Todo ello, aunque el centro privado acreditase que tenía una demanda de matrícula suficiente ${ }^{40}$ que justificase acceder a una financiación pública ${ }^{41}$. La legislación, en efecto, amparaba esa decisión denegatoria en la medida en que, de modo explícito, nunca reconoció que la demanda social, esto es, las preferencias manifestadas por los padres, fuese un criterio que fuera vinculante a la hora de planificar la oferta educativa financiada con fondos públicos. Los tribunales han confirmado repetidas veces la denegación del concierto, pues las leyes amparaban esta política pública, y no han entendido que esas normas legales fuesen incompatibles con la ley fundamental ${ }^{42}$.

En cierto sentido, esta jurisprudencia es coherente con una configuración legal en la LODE de la libertad de enseñanza que optó por financiar la oferta, es decir, con financiar los establecimientos docentes, no la demanda. Las preferencias de los padres y apoderados devienen, pues, poco relevantes a la hora de decidir concertar un colegio, con todos los interrogantes que suscita, desde el orden constitucional, una arquitectura legal que depara este trato a la libertad de enseñanza.

administrativo especial de financiación a favor de tercero: cfr. De Los Mozos (2014), p. 32, y Guardia y MANENT (2015), pp. 183-184. Esta última posición es la asumida en este trabajo.

40 En este trabajo se entiende como "demanda de matrícula" al número de preinscritos o solicitantes de un establecimiento docente concertado en primera opción.

41 Con las excepciones, ya citadas, de la Comunidad Autónoma del País Vasco y Madrid. En menor medida también la Comunidad Foral de Navarra.

42 Cfr. De los Mozos (2007), pp. 117-148. 
Recuérdese, como hemos señalado con precedencia, que el TC español no reconoció el derecho al concierto educativo como derivado directamente de la Constitución dentro del contenido esencial del derecho fundamental de libertad de enseñanza. Debe, pues, ser regulado y dotado de contenido por el legislador. La LODE configuró un derecho al concierto que no es incondicional, pues se supedita a un concepto jurídico indeterminado denominado "necesidades escolares reconocidas", lo que erige a este concepto en árbitro de las peticiones de concierto.

De algún modo, este modo de proceder es análogo al primer desarrollo e implantación en el derecho francés de la ley Debré, de 1959, precedente del sistema español. En efecto, durante los primeros años de aplicación de esta norma, la inclusión de un establecimiento privado en el régimen de asociación (établissements sous contrat d'association), que implica financiación pública, estaba supeditada a la exigencia de una necesidad escolar reconocida (le besoin scolaire reconnu). Esta ley, por lo tanto, únicamente tenía en cuenta las necesidades cuantitativas de la demanda escolar: solo en caso de que los colegios públicos no fueran capaces de absorber la demanda escolar cabía la asociación de un colegio privado.

Esta perspectiva legal cosechó abundantes críticas en Francia, pues en definitivas cuentas se condenaba a la enseñanza asociada a la precariedad y a una suerte de subsidiariedad con respecto a la estatal ${ }^{43}$. Por ello esta norma fue reformada en 1971 en este punto. Se añadió que "la necesidad escolar" debía ser apreciada, entre otras cuestiones, también en función del principio de la libertad de enseñanza. Lo que permitía jurídicamente a las autoridades públicas tener en cuenta elementos cualitativos a la hora de admitir nuevos colegios al régimen de asociación, tales como la elección de los padres del centro para sus hijos. Ahora bien, el giro copernicano de la ley Debré se dio en una decisión del Conseil d'État de 25 de abril de $1980^{44}$. En efecto, este importante ente constitucional apreció que unas necesidades de escolarización ya cubiertas por establecimientos públicos no justificaban plenamente la negativa de la administración a suscribir nuevos contratos de asociación. El Conseil d'État afirmó que esta era una interpretación restrictiva, por lo que avaló la necesidad de considerar la demanda social (esto es, las preferencias de los padres, designadas como elementos cualitativos en la

43 Cfr. Monchambert (1983), p. 147, y Díaz (1992) pp. 159-162.

44 Se puede acceder a esta en: Actualité Juridique Droit Administratif, de 20 de septiembre de 1980, pp. 491-494. 
terminología francesa) a la hora de otorgar o denegar la asociación de nuevos establecimientos educativos.

Diversos gobiernos galos han intentado con posterioridad, sin éxito, retornar a la literalidad de la ley de 1959 para hacer a la educación privada (de nuevo) subsidiaria de la estatal. Este intento (y otros) para dar primacía a la iniciativa estatal en la educación frente a la iniciativa social tuvo que enfrentarse a importantes movilizaciones sociales, y en especial con la relevante decisión del Consejo Constitucional francés de 18 de enero de 1985.

En efecto, la Loi No 85-97, du 25 janvier $1985^{45}$, de algún modo hacía volver a la Ley Debré a su primitiva redacción, es decir, la de 1959, de tal manera que los establecimientos públicos y los asociados estarían coordinados por las administraciones.

Y ello porque la suscripción de los contratos entre la enseñanza privada y el Estado estarían condicionados a las normas y criterios para la apertura y supresión de las aulas de la enseñanza pública. Se intentó priorizar las necesidades cuantitativas sobre las denominadas necesidades cualitativas de escolarización, revirtiendo la reforma de 1971 de la Ley Debrét

No obstante, contra esta se interpuso un recurso previo de inconstitucionalidad que el Consejo Constitucional estimó de modo indirecto. Se realizó una interpretatio secundum constitutionem, según la cual la planificación escolar (Carte scolaire) es aplicable a la enseñanza estatal, pero tiene un rango secundario en la enseñanza privada asociada ${ }^{47}$.

45 Loi No 85-97 du 25 janvier 1985 modifiant et complétant la Loi No 83-663 du 22 juillet 1983 et portant dispositions diverses relatives aux rapports entre l'Etat et les collectivités territoriales.

46 Cfr. Delvolvé (1985), pp. 624-625.

47 La argumentación del Consejo de Estado es brillante: Delvolvé (1985), pp. 626-627: «C’est ici que la fonction d'interprétation du Conseil constitutionnel s'est manifestée avec le plus d'éclat, faisant dire au texte, sinon le contraire de ce qu'il avait voulu exprimer, en tout cas, beaucoup moins que ce qu'il contenait. Le Conseil a rapproché le texte litigieux de l'article 4, toujours en vigueur, de la Loi du 31 décembre 1959, selon lequel les établissements privés peuvent demander à passer avec l'État un contrat d'association s'ils répondent, a un 'besoin scolaire reconnu'. Le Conseil d'Etat avait déjà eu I'occasion de juger que cette expression ne recouvrait pas seulement des besoins quantitatifs mais encarre des besoins qualitatifs (...). Le Conseil constitutionnel confirme cette solution en la renforçant: 'le besoin scolaire reconnu comprend des éléments quantitatifs tels que la demande des familles et le caractère propre de l'établissement d'enseignement'. En conséquence, les dispositions de l'article 27-3 ont pour objet, non de donner une énumération exhaustive des éléments servant à déterminer si l'établissement privé répond à un 'besoin scolaire reconnu', mais seulement de préciser quels sont les éléments à prendre en compte pour apprécier l'existence d'un 'besoin scolaire reconnu' sous son seul aspect quantitatif». Sobre el reparto competencial sobre el mapa o planificación escolar producido por la Loi No 85-97 du 25 janvier 1985: cfr. Douence (1985). Para una visión sintética 
Volviendo al caso español, se puede afirmar que, con carácter general, durante los últimos 30 años la planificación educativa pública ha prevalecido sobre cualquier otra consideración, como en la primera aplicación de la Ley Debré en Francia. No ha habido la evolución legislativa y jurisprudencial francesa a la que hemos hecho referencia, que ha dotado de mayor autonomía y alcance a la libertad de enseñanza en detrimento de los mapas escolares y la regulación pública ${ }^{48}$. Esa planificación, en donde ha habido una administración educativa propicia a aumentar la oferta educativa concertada, posibilitó el aumento de establecimientos docentes no estatales sostenidos con fondos públicos, caso en el que se encuentra de manera destacada la Comunidad de Madrid ${ }^{49}$.

Sin embargo, como hemos adelantado al principio de este trabajo, es necesario en este momento añadir que, quizás, el sistema español podría empezar a cambiar en este punto, habida cuenta de la reforma educativa aprobada en el año 2013. Siempre en el bien entendido de que esa reforma se mantenga en el tiempo y pueda ser aplicada por los tribunales. En efecto, la Ley Orgánica No 8/2013, de 9 de diciembre, para la mejora de la calidad educativa (Lomce), ha introducido una tímida clausula inexistente hasta el momento, que viene a matizar lo realizado en las tres últimas décadas. Se añade que, a la hora de planificar la oferta de plazas, se tome en consideración, entre otras razones, la demanda social ${ }^{50}$. El legislador emplea este concepto jurídico indeterminado ("demanda social"), que abre la posibilidad a que la administración educativa pueda atender a las preferencias de las familias a la hora de construir un nuevo colegio público, concertar uno privado, o mantener o ampliar uno ya suscrito ${ }^{51}$. Ciertamente no se constituye un derecho público subjetivo ${ }^{52}$ a suscribir un concierto

de la financiación pública en Francia de los establecimientos docentes privados tras las polémicas citadas: cfr. Dupont-Marillia (2007), pp. 74-77.

48 Solamente se encuentran algunas sentencias del Tribunal Supremo español que anulan la pretensión de algunas CC. AA. de añadir más requisitos para concertar un centro privado: sentencia de 22 de julio de 2008 (CJ 112761/2008). O que anulan una negativa a concertar por la ausencia de motivación de la decisión que supera la discrecionalidad administrativa, y llega a la arbitrariedad: SSTS de 30 de enero de 2007 (CJ 2471/2007) y de 18 de julio de 2008 (CJ 96612/2008).

49 Cfr. Carpintero y Siemiatycki (2015).

50 Este concepto jurídico se recoge en el art. 109.2 LOE.

51 Cfr. art. 109.2 LOE. También -y este punto también es novedoso- la posibilidad de conceder el uso de suelo público para la construcción y gestión de un colegio concertado: art. 116. 8 LOE, en la redacción dada por el art. 70 Lomce: cfr. GuARDia (2012), pp. 12-29.

52 Con la categoría "derecho público subjetivo", en este trabajo, aludo genéricamente "a aquellos derechos que los particulares ostentan frente al Estado o, con mayor precisión, frente a cualesquiera Poderes Públicos. 
con la administración, pero supone un criterio que, a nuestro juicio, podrá ser valorado, en su caso, por los órganos jurisdiccionales si han de enjuiciar una denegación arbitraria de solicitud de concierto que estuviese avalada por una notoria demanda social. En ese sentido, el art. 106.1 de la Constitución Española, que constitucionalizó la inexistencia de comportamientos de las Administraciones Públicas inmunes al control judicial, avala que los particulares puedan invocar antes los tribunales contenciosoadministrativos la repetida "demanda social" 53 .

\section{II.2.2. La educación: ¿Servicio público o servicio de interés público?}

Hay que subrayar que en el fondo de este debate subyace una cuestión de gran calado jurídico-constitucional. Se trata de determinar cuál es la naturaleza jurídica del derecho a la educación que los poderes públicos deben garantizar, por mandato constitucional. En otras palabras, si estamos ante un servicio público o ante un servicio de interés público. Se trata de un debate bipolar en el que hay elementos normativos que avalan interpretar que los conciertos escolares son una herramienta para la financiación pública de la enseñanza privada ${ }^{54}$-en cuyo caso se entenderá que la educación es un servicio de interés público- y otros datos jurídicos postulan que, por el contrario, los conciertos constituyen una prestación privada de la enseñanza pública, con lo que en este segundo caso estaríamos antes una especie de contrato administrativo de gestión de un servicio público 55 o -de acuerdo con la última legislación española- un contrato administrativo de concesión de servicios.

En un sentido más técnico, no son todos los derechos oponibles a los Poderes Públicos, sino tan sólo aquéllos que están sometidos al derecho administrativo; es decir, quedan fuera los derechos subjetivos que surgen frente a la Administración cuando ésta actúa con sujeción al derecho privado": Díez-Picazo (2008), p. 41.

53 La postura que defendemos habilita a los tribunales a corregir la denegación infundada de solicitudes de concierto educativo. Esta posibilidad descansa en la diferencia entre potestad discrecional y concepto jurídico indeterminado. Y en la diferente intensidad (legítima) de control judicial de la actuación de los poderes públicos en uno u otro caso. Como es sabido, la discrecionalidad constituye "un margen de decisión que la ley deja explícitamente o reconoce implícitamente a la Administración. Cualquier opción que la Administración adopte en ese margen se considera válida (...) y no será admisible una revisión de esa decisión por los tribunales", en cambio "la ley recurre a unos conceptos generales porque ella es materialmente incapaz de concretarlo en los múltiples casos en que puede plantearse su aplicación (...) la aplicación por la administración de los conceptos jurídicos indeterminados puede ser revisada por los tribunales": EsTEVE (2017), pp. 198-109. Cursiva añadida.

54 Cfr. De los Mozos (2014), pp. 36-36.

55 Esta segunda opinión aparece en Romea (2003), pp. 109-115. 
En efecto, la legislación española de desarrollo del art. 27 de la Carta Magna ofrece elementos de juicio contradictorios, habida cuenta de que el art. 47.1 de la LODE entiende la educación como un servicio público, y a la actividad desarrollada por los colegios acogidos al régimen de conciertos como entes instrumentales de la administración pública educativa. Este artículo permaneció vigente durante 17 años, desde el año 1985 hasta 2002, cuando fue suprimido ${ }^{56}$. Con todo, en ningún precepto de la LODE se reserva al poder público algún ciclo o tramo del sistema educativo, lo que conlleva la dificultad de dilucidar qué quería decir el legislador con el concepto jurídico "prestación del servicio público de la educación" 57 . Otros preceptos legales aún vigentes mantienen la controversia y la ambigüedad, como el art. 108.4 de la $\mathrm{LOE}^{58}$.

Este último precepto, y otros análogos y derogados, ha permitido a parte de la doctrina española emplear el concepto de servicio públicos9 aplicado al ámbito educativo y extender su alcance a los conciertos ${ }^{60}$. A nuestro juicio, en muchos autores subyace -de modo consciente o no- como ideal que sean los poderes públicos los que satisfagan de modo directo todas las necesidades educativas de la ciudadanía, y contemplan cualquier otro tipo de solución como una etapa de minoría de edad del Estado social.

56 Es derogado por la Ley Orgánica No 10/2002, de 23 de diciembre, de Calidad de la Educación (VI Legislatura: 1996-2000. Presidente José María Aznar López).

57 También la última ley del régimen franquista expresaba que la educación "a todos los efectos tendrá la consideración de servicio público fundamental": art. 3o de la Ley General de Educación de 1970. Cfr. MARTínez López-MuÑIz (2007), p. 52.

58 Para ser exactos, la locución servicio público aparece cinco veces más en la LOE, pero todas ellas en el preámbulo de la ley. Esta norma se promulgó en la VIII Legislatura (2004-2008), siendo presidente José Luis Rodríguez Zapatero.

59 GurrutXaga y Satrústegui (2010), p. 107. Y también Cotino (2014), pp. 423-424.

60 Cfr. Fernández (2007), pp. 421-455: "El servicio público de la educación ha podido prestarse, desde sus orígenes, o bien por los poderes públicos directamente, o bien por la iniciativa privada. Hasta el punto que, a los efectos de la propia intervención administrativa sobre la titularidad de los centros, es posible identificar tres modelos de prestación del servicio público educativo: el público propiamente dicho; el privado concertado o intervenido intensamente, y el privado intervenido más levemente, en el que el centro educativo viene a ser un prestador privado de un servicio público más desdibujado" (p. 427). La cursiva es nuestra. Hay que señalar, por seguir con las alusiones al régimen francés que tanto ha influido en España, que ni la Ley Debré ni sus posteriores reformas usan la expresión «servicio público». Por el contrario, hay autores y comentaristas franceses que la eluden y usan otros términos. En ese sentido, RIVERO (1978) usa "activités privées d'intérêt général» (p. 567) o "activité privée d'intérêt public» (p. 568). Con todo, hay autores que sostienen con contundencia que los établissements sous contrat d'association prestan un servicio público, a modo de ejemplo, Durand-Prinborgne (1988), pp. 590-591. 
Como aval de esta posible interpretación -que adelantamos que no compartimos-, hay que reconocer que la terminología legal utilizada podía sugerir que la educación concertada era una de las formas de gestión indirecta de un servicio público. En términos estrictos vendría a constituir un ejemplo del denominado "contrato de gestión de servicios públicos" 61 . En efecto, la legislación contractual del sector público español permitía hasta 2017 que "La Administración podrá gestionar indirectamente, mediante contrato, los servicios de su competencia, siempre que sean susceptibles de explotación por particulares"62. Este contrato administrativo tenía varias modalidades. Un sector doctrinal identificaba la financiación de los centros docentes privados con la modalidad contemplada en el art. 276 c) del Texto Refundido de la Ley de contratos del sector público de 2011. Este es su tenor literal: “c) Concierto con persona natural o jurídica que venga realizando prestaciones análogas a las que constituyen el servicio público de que se trate".

Ahora bien, en el año 2017 se aprobó una nueva Ley de contratos del sector público, en la que desaparece el "contrato de gestión de servicio público", que es reemplazado por el "contrato de concesión de servicios". A diferencia de la anterior figura contractual, la nueva no se limita a servicios públicos, sino "a la gestión de un servicio cuya prestación sea de su titularidad o competencia"63. Este matiz permite a los entes del sector público una gestión indirecta, mediante contrato, de un servicio de su competencia, siempre que sean susceptibles de explotación económica por particulares ${ }^{64}$. Y ello sin circunscribirlos exclusivamente a servicios públicos stricto sensu, sino a cualesquiera que una administración sea capaz de prestar, también en competencia con otros agentes económicos. En ese sentido, el argumento jurídico según el cual la enseñanza es un servicio público, y los conciertos educativos la prestación indirecta de este, pierde una de sus tradicionales evidencias.

Como quiera que sea, a nuestro juicio, tanto la calificación jurídica del concierto económico con centros docentes privados como "contrato de gestión de

61 Cfr. Martínez López-Muñiz (2007), pp. 54-55.

62 Art. 275.1 del Real Decreto Legislativo No 3/2011, de 14 de noviembre, por el que se aprueba el Texto Refundido de la Ley de contratos del sector público (derogado): cfr. BlanQuer (2013), pp. 797-808.

63 Art. 15 de la Ley No 9/2017, de 8 de noviembre, de Contratos del Sector Público.

64 Art. 284 de la Ley No 9/2017, de 8 de noviembre, de Contratos del Sector Público: "En ningún caso podrán prestarse mediante concesión de servicios los que impliquen ejercicio de la autoridad inherente a los poderes públicos”. 
servicios públicos" o como "contrato de concesión de servicios" no se ajusta a la realidad.

Y todo ello por que estas dos calificaciones presentan importantes obstáculos constitucionales para ser aceptadas si se realiza una lectura sistemática y finalista de la ley fundamental y del ordenamiento jurídico español, habida cuenta que del marco constitucional y legal se deriva que la educación no es un servicio público, ni un servicio sobre el cual las administraciones puedan reivindicar una competencia exclusiva, sino una actividad esencialmente libre.

En ese sentido, y siguiendo Martínez López-Muñiz, entendemos que la educación es un servicio esencial o de interés general que constituye una libertad pública que los poderes públicos han de garantizar y ordenar "del mejor modo, sin vaciar de contenido tales libertades, ni condicionarlas tal modo que resulte en la práctica una quimera salvo para 'los que puedan pagárselas'. Sin olvidar que (...) la aplicación de fondos públicos a la efectividad de las libertades públicas y los derechos fundamentales no puede ser empleada para restringirlos ni para condicionarlos del modo que considere más oportuno el gobernante de turno"65.

En efecto, hay que considerar que la enseñanza concertada es una actividad que la administración no puede asumir como propia ${ }^{66}$. En la actualidad, los conciertos educativos son el cauce por el cual los poderes públicos aseguran una educación gratuita en libertad. Si los titulares de centros privados (los sostenedores) tienen el "derecho a establecer el carácter propio"67, así como a "acogerse al régimen de conciertos en los términos legalmente establecidos" 68 , ni prestan un servicio público por delegación de la administración educativa, ni prestan tampoco de modo indirecto un servicio de titularidad pública que también tiene proveedores privados.

Es capital subrayar que la educación no es un servicio público también porque la neutralidad ideológica y religiosa exigida en la escuela estatal lo impide. En efecto, el servicio público es incompatible con la actividad de organizaciones de tendencia ${ }^{69}$, como son $-\mathrm{o}$ pueden ser- los colegios concertados.

65 Martínez López-MuÑIz (2006b).

66 Cfr. Mestre (2009), pp. 121-145.

67 Art. 115.1 LOE.

68 Art. 116.1 LOE.

69 Cfr. IruReta (2003), pp. 235-236: [la organización de tendencia] "Se trata de organizaciones que no pueden ser configuradas como simples manifestaciones de la libertad de empresa o de la mera iniciativa económica; sino que su base de constitución se encuentra radicada en el reconocimiento de ciertos derechos 
En ese sentido, la STC 5/1981, de 13 febrero, afirmó que en España "la libertad de enseñanza que explícitamente reconoce nuestra Constitución (art. 27.1) puede ser entendida como proyección de la libertad ideológica y religiosa y del derecho a expresar y difundir libremente los pensamientos, ideas y opiniones que también garantizan y protegen otros preceptos constitucionales". Por lo que la libertad de creación de centros docentes (concertados o no) incluye derecho al ideario o carácter propio de aquellos que no son de titularidad estatal. Y este ideario puede fundarse en motivos religiosos, ideológicos, pedagógicos u otros análogos.

Es decir, en el caso de calificar a los conciertos como un modo de gestión indirecta de un servicio público (o de un servicio de interés general prestado por un poder público), los contratistas no podrían poseer un carácter propio y transmitir un ideario, posibilidad reconocida legal, constitucional e internacionalmente en España a los colegios concertados, y que pertenece al núcleo esencial de la libertad de enseñanza, como hemos detallado al principio de este trabajo, al describir el contenido de los derechos educativos en el art. $27 \mathrm{CE}^{70}$.

Para finalizar este epígrafe, concluimos que calificar la enseñanza como un servicio público en sentido estricto plantea -como hemos señalado- irresolubles problemas constitucionales relativos a la preservación de la identidad de los establecimientos privados, a su ideario, a su autonomía y, en definitiva, a la pluralidad de ofertas educativas.

\section{II.2.3. La descentralización política en España}

Hemos afirmado con precedencia (epígrafe I.2) que el TC permite al legislador español cierto margen normativo para establecer una regulación educativa básica que favorezca o, por el contrario, dificulte la concertación de nuevos centros educativos privados.

Ahora bien, esta última afirmación debe ser matizada por la influencia de otro rasgo constitucional que la Constitución de 1978 deparó para España: la distribu-

esenciales de los que son titulares en razón de un claro ideario de actuación”. Se trata, en definitiva, de “organizaciones institucionalmente expresivas de una ideología” o "ideario". Y también OTADUY (1986), p. 323.

70 En la doctrina encontramos algunas interesantes posiciones intermedias, como BÁEZ (2016), p. 331: "Por todo lo cual, llegamos a la conclusión de que sería posible denominar la educación, pública y concertada, como de servicio público, siempre y cuando esto no impida la expansión de la libertad de enseñanza, no implicando la titularidad del servicio educativo por parte de los poderes públicos así como tampoco un título de cobertura que sirva de excusa para justificar un dirigismo de los centros por parte de la Administración ni un exceso reglamentista que burocratice el sistema educativo". 
ción territorial del Poder. En la introducción de este artículo, hemos aludido a que uno de los principios informadores del sistema educativo español es el principio de compartición estatal entre Estado central y comunidades autónomas. En efecto, como es conocido, este país ha desarrollado uno de los sistemas constitucionales más descentralizados de Europa. En el ámbito de los derechos educativos, el art. 149.1.30a CE establece como competencia exclusiva del Estado central la regulación de las condiciones de obtención, expedición y homologación de títulos académicos y profesionales y las normas básicas para el desarrollo del art. $27 \mathrm{CE}^{71}$. Lo que permite que la competencia ejecutiva pueda ser asumida por las comunidades autónomas, posibilidad que ha sido implementada por todas ellas en todos los Estatutos de Autonomía ${ }^{72}$. Hoy en día, por lo tanto, solo los establecimientos educativos de las Ciudades Autónomas de Ceuta y Melilla, sitas en el norte de África, dependen directamente del Ministerio de Educación ${ }^{73}$. El resto dependen de las administraciones de las comunidades autónomas, que ostentan todas las facultades ejecutivas tanto en los centros estatales sitos en su territorio como en los de iniciativa social, sean o no concertados ${ }^{74}$. Con todo, hay que recordar que el nervio de la regulación se desarrolla en la actualidad en una larga ley estatal, la LOE (Ley Orgánica de Educación), con 157 artículos y

71 Es fundamental, en ese sentido, el Decreto No 2.377/1985, de 18 de diciembre, por el que se aprueba el Reglamento de Normas Básicas sobre Conciertos Educativos. Este cuerpo reglamentario está vigente y no ha sido modificado nunca. Para ser preciso, se introdujo una corrección menor irrelevante en el año 1989 por Real Decreto No 139/1989, de 10 de febrero.

72 Cfr. Martínez López-Muñiz (2007), pp. 32-33. También posibilita la existencia de una legislación autonómica de desarrollo del art. 27 CE y de la legislación básica común a todo el Estado. Con todo, solo algunas comunidades autónomas han asumido estatutariamente esta competencia legislativa y han aprobado leyes educativas. Estas son: Ley No 12/2009, de 10 de julio, de Educación de Cataluña; Ley No 17/2007, de 10 de diciembre, de Educación de Andalucía; Ley No 6/2008, de 26 de diciembre, de Educación de Cantabria; Ley No 7/2010, de 20 de julio, de Educación de Castilla-La Mancha; Ley No 6/2014, de 25 de julio, Canaria de Educación no Universitaria, y la Ley No 4/2011, de 7 de marzo, de Educación de Extremadura. Otras CC. AA. han aprobado leyes en materia educativa para aspectos concretos como son medidas para reafirmar la autoridad del profesorado, para la convivencia en las aulas, para la educación de personas adultas, entre otras.

73 Hay que matizar que el Ministerio de Educación sostiene y gestiona directamente también algunos centros docentes fuera del territorio nacional, y realiza convenios con centros docentes privados extranjeros que se adecuan al sistema educativo español: Real Decreto No 1.027/1993, de 25 de junio, por el que se regula la acción educativa en el exterior.

74 Martínez López-Muñiz (2007), pp. 46-47. Se mantiene, no obstante, la existencia de una "Alta Inspección" por parte del Estado que, en la práctica, no ha funcionado, pese a derivarse directamente del art. 27.8 CE. En efecto, durante décadas se ha renunciado a la regulación y desarrollo de la citada Alta Inspección, lo que ha provocado el incumplimiento legislativo impune en educación por parte de algunas administraciones educativas autonómicas: cfr. MANENT y GUARDiA (2016). 
43 disposiciones adicionales. Ahora bien, esta extensión de la LOE podría inducir a pensar que debería existir una gran homogeneidad entre las CC. AA. en lo relativo al sostenimiento público de los establecimientos docentes privados. Como se verá, la realidad dista mucho de ser así.

¿Cuál ha sido la consecuencia de este ambicioso proceso de descentralización política en España en el ámbito educativo en lo relativo a la financiación pública de los establecimientos docentes de iniciativa social? La respuesta a esta pregunta no está exenta de controversia. Cabe precisar, en todo caso, que por razones de espacio no podremos extendernos a todas las cuestiones relacionadas con la descentralización educativa, sino que nos circunscribimos a aquellas que inciden en la configuración del sostenimiento económico público de la concertada. En ese sentido, no nos referiremos a las ásperas controversias sobre las lenguas vehiculares en la enseñanza, dado el carácter plurilingüístico de España ${ }^{75}$; a los continuos litigios en algunas comunidades autónomas sobre el estatuto jurídico de la asignatura de religión en los planes de estudios ${ }^{76}$, o los problemas jurídicos sobre la convivencia escolar y la calidad de la enseñanza, que obtiene un desempeño muy dispar entre CC. AA.77.

En nuestra opinión, en lo atinente a este trabajo, la principal y discutible consecuencia del denominado Estado de las Autonomías ha sido que haya comunidades autónomas que han financiado numerosos colegios de iniciativa social, como País Vasco o Madrid, y comunidades donde la política pública ha sido, precisamente, la inversa, como Andalucía, Extremadura o Castilla-La Mancha. También entendemos relevante mencionar la polémica en algunas CC. AA. con respecto a la financiación pública de la educación diferenciada por sexos, con casos en Andalucía, Castilla-La Mancha, Cataluña o Asturias.

Vamos a proceder al análisis ponderado de ambas cuestiones a continuación.

En cuanto a la dispar financiación de la escuela concertada en España, para poder juzgar con más elementos de juicio, exponemos en primer lugar algunos datos estadísticos extraídos de las publicaciones oficiales del Ministerio de Educación.

En España, durante el curso 2017-2018, el alumnado en enseñanzas no universitarias ascendía a 8.158 .605 personas $^{78}$. Esta cifra incluye a todos los es-

75 Nos remitimos a cuando afirmamos en MANENT y Guardia (2016).

76 Cfr. Guardia (2014).

77 Cfr. GonzÁlez-Varas IbáNez (2014).

78 No se incluyen las denominadas enseñanzas de régimen especial, como son las artes plásticas y diseño, música, danza, arte dramático y deportivas. 
tudiantes hasta los 18 años. En lo relativo a los ciclos educativos obligatorios, en la educación primaria (6-12 años de edad) el 67,8 \% está escolarizado en centros estatales, el 28,5\% en centros concertados, y el 3,7 \% en centros privados no concertados. En la Educación Secundaria Obligatoria (12 a 16 años de edad), la distribución es la siguiente: $65,6 \%$ en públicos, 30,6 \% en concertados y 3,8 \% en privados no concertados. Por último, en Bachillerato (16 a 18 años), que es una etapa no obligatoria, el 74,5\% en públicos, $11,1 \%$ en concertados y 14,4 $\%$ en privados no concertados ${ }^{79}$.

Ahora bien, cuando desagregamos estos datos por CC. AA., encontramos diferencias muy notables. Sin afán de exhaustividad, podemos resaltar algunas cifras de la distribución del alumnado no universitario por titularidad/financiación y comunidad autónoma en el curso 2016-201780:

- País Vasco: 50,8 \% en centros docentes públicos, 48,4 \% en centros docentes concertados, y $0,8 \%$ en centros docentes privados no concertados.

- Madrid: 54,3\% en centros docentes públicos, 30,1\% en centros docentes concertados, y $15,6 \%$ en centros docentes privados no concertados.

- Andalucía: 74,3\% en centros docentes públicos, 20,4\% en centros docentes concertados, y $5,3 \%$ en centros docentes privados no concertados.

- Castilla-La Mancha: 81,1\% en centros docentes públicos, 15,2 \% en centros docentes concertados, y $3,7 \%$ en centros docentes privados no concertados ${ }^{81}$.

La explicación de unos porcentajes tan dispares en unos territorios tan próximos desde todos los puntos de vista (geográfico, cultural, de marco constitucional y legal) no responde a una menor demanda social de la enseñanza concertada en algunas comunidades autónomas con respecto a otras. A nuestro juicio, como hemos afirmado, responde a consideraciones metajurídicas o de oportunidad en las administraciones educativas de las comunidades autónomas. En efecto, la interpretación de la CE realizada por el TC brinda una amplia discrecionalidad a los poderes públicos en esta materia, posibilidad que los ejecutivos autonómicos han implementado sin dudar. En ese sentido, Vidal afirma, acertadamente, que "la eficacia y garantía de los derechos educativos son más o menos pacíficas en función del Comunidad Autónoma en la que se habite, dependiendo del 'color'

\footnotetext{
79 Ministerio de Educación y Formación Profesional (2018), p. 4.

80 Último curso con datos oficiales consolidados. Los porcentajes son comparables con el curso actual. No ha habido variaciones reseñables en las últimas décadas.

81 Ministerio de Educación y Formación Profesional (2018), p. 6.
} 
político del gobierno correspondiente" 82 . En otras palabras, dependiendo del lugar de residencia, las familias españolas tienen un alcance de sus derechos educativos diferentes.

Sin embargo, el marco constitucional español no permite una disparidad y unas políticas públicas en materia educativa tan diferentes entre las distintas CC. AA. La CE reserva al Estado central el establecimiento de un marco común educativo que garantice la igualdad en el ejercicio de derechos y deberes (art. 149.1.1 ${ }^{\text {a }}$ CE) y específicamente le reserva el desarrollo básico de los derechos educativos (art. 149.1.30a CE). No se pueden importar modelos constitucionales comparados sin forzar la Carta Magna.

Con todo, en este punto hay que añadir alguna consideración más, habida cuenta del amplio margen de apreciación que el TC deja en manos de las administraciones educativas a la hora de concertar nuevos centros escolares. En efecto, ¿esa discrecionalidad administrativa tiene límites?, ¿las CC. AA. pueden implementar un modelo que haga desaparecer la concertada? A nuestro juicio, esa potestad tiene límites. Junto a la limitación propia de toda potestad administrativa, en este caso concurre otro límite que deriva directamente de la Carta Magna. Y es que cualquier normativa autonómica de desarrollo del art. $27 \mathrm{CE}$, o cualquier actividad administrativa de ejecución de esta, debe respetar un "mínimo de sostenimiento financiero a los centros educativos privados que cumplan las condiciones legales" 83 . En otras palabras, la pluralidad de opciones en manos de los legisladores autonómicos no les permite suprimir o prohibir la educación concertada, tal y como está configurada en la LOE. Y, en todo caso, si el legislador estatal decide suprimir el sistema de conciertos educativos establecido en España por la LODE en 1985, debe ofrecer por mandato constitucional un modelo de financiación distinto de conformidad con el repetido art. 27.9 CE. Carecen, pues, de fundamento constitucional aquellas opciones políticas que quieren suprimir sin más trámite los conciertos educativos en España, y sustituirlos por una oferta educativa en centros de titularidad pública. Ello solo sería posible si se procede a una reforma de la Constitución.

Hay que añadir, simultáneamente, que también estaría vedado por la ley fundamental una actividad administrativa, no propiamente legal, de supresión o no renovación de los conciertos educativos, hasta hacerlos desaparecer. Sería

82 VIDAL (2017), p. 12.

83 Díez-Picazo (2008), p. 503. 
propiamente una práctica administrativa que, entre otras cosas, los tribunales contencioso-administrativos tendrían que anular por una flagrante desviación de poder que, como es conocido, constituye una herramienta para controlar o reducir la discrecionalidad administrativa ${ }^{84}$.

Dejando de lado los diferentes porcentajes de educación concertada entre las CC. AA., cabe aludir a otro problema sobre la descentralización política en España en el ámbito educativo. Como hemos anticipado, es el relativo a la denominada educación diferenciada por sexos (single-sex o igualmente designada como same gender education $^{85}$ ). Dentro de la oferta educativa en España, existen algunos centros docentes que han adoptado, dentro de su libertad pedagógica, una escolarización separada de niños y niñas ${ }^{86}$. Durante largas décadas han sido unos centros escolares que han desempeñado su tarea en todo el territorio español sin controversia alguna con las administraciones educativas. Algunos han accedido al concierto educativo, otros nunca lo han solicitado, y a otros se les ha denegado el concierto de modo análogo que al resto de centros privados en régimen de coeducación en que los alumnos de ambos sexos comparten aula. Lo cierto es que la legislación básica educativa no se hacía referencia específica alguna a estos centros, pues era pacífico que formaban parte de la pluralidad educativa del país ${ }^{87}$.

Lo cierto es que hace pocos años algunas administraciones educativas autonómicas empezaron a retirar conciertos educativos de modo unilateral, o no renovar los ya suscritos, únicamente por el hecho de ser establecimientos docentes de educación diferenciada ${ }^{88}$. Esto produjo una sorprendente circunstancia, en la que dependiendo de qué comunidad autónoma se trate, los padres podían

84 Sobre la desviación de poder: Esteve (2017), pp. 107-109. Recordemos que por desviación de poder se comprende el uso de una potestad administrativa para un fin distinto para la cual ha sido creada.

85 Charro (2013), p. 162.

86 Cfr. GonzÁlez-VAras IbÁÑez (2013), p. 2: «la enseñanza pública sigue, en la España actual, el régimen de la coeducación. Esto significa que los únicos centros que ofrecen educación diferenciada son los privados».

87 Cfr. Martínez López-Muñiz (2012), pp. 71-108, y también Nuevo (2014), pp. 226-230. Desde la perspectiva del derecho comparado, y con referencias a la jurisprudencia del TS alemán y español: cfr. EsTeVE (2013), pp. 4-13. Se alude a la STS Federal Alemán de 30 de enero de 2013, favorable a este modelo educativo. Se puede acceder a la sentencia alemana en www.bundesverwaltungsgericht.de.

88 Centenera SÁnchez-Seco (2014), p. 768: «A comienzos de la década anterior, una vez concluido el proceso de trasferencias sobre educación a las comunidades autónomas, asistimos a denegación de conciertos educativos en determinados contextos autonómicos, para aquellos centros en los que se estaba llevando a cabo un sistema de educación diferenciada. Esta decisión quedaba respaldada con el argumento de que el sistema de educación diferenciada constituye discriminación. La denegación de conciertos se puede localizar, por ejemplo, en los contextos autonómicos andaluz, castellano manchego, catalán o asturiano». 
acceder a centros docentes concertados que siguen este modelo pedagógico o, por el contrario, solo les quedaba la solución de acudir a uno no concertado, cuyo coste escolar era significativamente más elevado y difícilmente accesible para muchas familias.

Como es plausible pensar, esta agresiva política pública amplió el frente de la "guerra escolar», si es legítimo usar esta imagen a la que hemos aludido al principio de este trabajo. La consecuencia es que numerosas asociaciones de madres y padres, así como los titulares de centros docentes, acudieron a los tribunales. Se puede afirmar que hasta el año 2008, con carácter general, los órganos jurisdiccionales han dado la razón a los ciudadanos y han condenado a las administraciones autonómicas a mantener los conciertos educativos ${ }^{89}$. Por todas, se puede aludir a la sentencia del Tribunal Supremo (en adelante STS) de 26 de junio de 2006, que concluyó taxativamente que la educación diferenciada no era discriminatoria, sino que constituía "parte del derecho de los titulares de una institución de enseñanza a definir el carácter propio, y del derecho de los padres a elegir el centro en que deseaban escolarizar a sus hijos» ${ }^{90}$. No obstante estos pronunciamientos judiciales, algunas CC. AA. seguían condicionando la renovación del concierto a que los centros educativos asumieran la coeducación.

Ahora bien, en el año 2008 se producen algunas SSTS que, rompiendo con la jurisprudencia precedente, avalan en cierta medida la retirada de conciertos educativos $^{91}$. Lo paradójico es que, con posterioridad a esa fecha, recaen nuevas resoluciones judiciales del TS que vuelven a avalar los conciertos a la educación diferenciada. En este punto, hay que aludir a la Ley Orgánica No 2/2006, de 3 de mayo, de Educación (LOE). En lo que ahora nos interesa, hay que subrayar que es la primera norma española que hace alguna alusión expresa a la educación diferenciada. Desafortunadamente, no contribuyó a aportar seguridad jurídica -como se verá-, sino que agudizó las contradicciones de la descentralización política en España en materia educativa.

89 Cfr. GonZÁlez-Varas Ibá̃̄ez (2013), p. 11: «hasta el año 2008, puede decirse que, en términos generales, este modelo educativo no sólo encontró respaldo jurisdiccional, sino que los tribunales no apreciaron que fuera un obstáculo para que estos centros recibieran fondos públicos ni tuvieran que sobrellevar otras cargas impuestas por la Administración para desarrollar su proyecto».

90 Ibídem, p. 11.

91 En concreto, las STS de 16 de abril de 2008, recurso de casación No 675/2005; STS 11 de julio de 2008, recurso de casación No 689/2005: CENTENERA SÁnCHEZ-SECo (2014), pp. 768-769. 
En efecto, la LOE apunta en dos ocasiones a la educación diferencia. Una de manera implícita y otra de manera explícita. Ambas tienen carácter básico, esto es, son desarrollo de las competencias exclusiva estatales y, por tanto, se imponen a las CC. AA. Las referencias son el art. 84.3 y la Disposición Adicional vigésimo quinta. Las analizamos a continuación brevemente.

El art. 84.3 LOE, relativo a la escolarización en centros públicos y privados concertados, afirmó que «En ningún caso habrá discriminación por razón de nacimiento, raza, sexo, religión, opinión o cualquier otra condición o circunstancia personal o social». ¿El veto a la discriminación por razón de sexo implica la imposibilidad de concertar la educación diferenciada? Algunas comunidades autónomas entendieron que sí y otras que no.

La Disposición Adicional vigésimo quinta de la LOE, sobre el Fomento de la igualdad efectiva entre hombres y mujeres, afirmó: "Con el fin de favorecer la igualdad de derechos y oportunidades y fomentar la igualdad efectiva entre hombres y mujeres, los centros que desarrollen el principio de coeducación en todas las etapas educativas, serán objeto de atención preferente y prioritaria en la aplicación de las previsiones recogidas en la presente Ley, sin perjuicio de lo dispuesto en los convenios internacionales suscritos por España». Nuevamente tenemos una redacción ambigua. La referencia a los convenios internacionales es una alusión directa a la Convención relativa a la Lucha contra las Discriminaciones en la Esfera de la Enseñanza de la Unesco, de 1960. Este tratado internacional afirma que este modelo educativo no es discriminatorio siempre que se ofrezcan facilidades equivalentes en el acceso a la enseñanza a los dos sexos, se disponga de un personal docente igualmente calificado, así como de locales escolares y de equipo de igual calidad, y se permita seguir los mismos programas de estudio o programas equivalentes. Todas estas condiciones se cumplen en todas las CC. AA. españolas, por lo que parece que no habría motivo en derecho que justificase la denegación por parte de las CC. AA. de los conciertos educativos solo por esta razón. Ahora bien, algunas CC. AA. alegaban que esa Disposición Adicional preveía una cierta preferencia por la coeducación, lo que justificaba su decisión de eliminar la financiación a la educación diferenciada.

De todo ello se concluyó que estas novedades de la LOE no consiguieron menguar en absoluto la conflictividad jurisdiccional en algunas CC. AA., empeñadas en continuar su peculiar guerra regional contra el sostenimiento económico público de este modelo educativo. Por el contrario, sirvieron de aval para nuevas 
SSTS a partir del año 2010, que avalaron la no renovación de conciertos a colegios de educación diferenciada en contra de la jurisprudencia mayoritaria previa ${ }^{92}$.

El legislador básico estatal quiso zanjar esta controversia en la reforma de la LOE promovida por la Ley Orgánica No 8/2013, de 9 de diciembre, para la mejora de la calidad educativa (Lomce). A tal efecto se añadieron dos párrafos (que continúan vigentes) al art. 84.3 LOE, que limitan los efectos de la descentralización. En síntesis, se estableció que los centros docentes acogidos al modelo de educación diferenciada deben acceder a los conciertos en condiciones de igualdad con el resto de centros privados, sin dejar margen a las CC. AA. para discriminarlos en este punto.

No obstante, esta innovación del art. 84.3 LOE fue impugnada ante el TC 93 . Este recurso pretendía la prohibición de la educación diferenciada en España o, subsidiariamente, proscribir que pudiesen suscribir conciertos educativos. La STC 31/2018, de 10 abril, desestimó íntegramente este recurso y estableció que la educación diferenciada constituye un modelo educativo que, en sí mismo, no causa discriminación ${ }^{94}$. Por otra parte, y lo que es más relevante en términos constitucionales, añadió que este método pedagógico forma parte del derecho de todo centro privado a establecer su carácter propio, que a su vez forma parte del contenido esencial de la libertad de enseñanza ${ }^{95}$. En otras palabras, el TC interpreta la Carta Magna de tal modo que ahora ni el legislador básico español, ni los legisladores autonómicos ni las administraciones educativas pueden retirar o no suscribir conciertos educativos por el mero hecho de que un establecimiento docente adopte la educación diferenciada por sexos.

En conclusión, a partir de este apartado se puede afirmar que es probable que se esté vulnerando la igualdad en el ejercicio de derechos y deberes de los españoles (art. 149.1.30ª $\mathrm{CE}$ en relación con el art. $14 \mathrm{CE}$ ) en el ámbito educativo al encontrarse políticas públicas tan diferentes entre comunidades autónomas en cuanto a la escuela concertada. Las posibilidades de escolarización en centros

\footnotetext{
92 Nos referimos a las controvertidas sentencias del TS español de 23 de julio de 2012 (CJ 110633/2012) y 24 de julio de 2012 (CJ 110636/2012), ambas con votos particulares disidentes de algunos magistrados. Estas resoluciones judiciales fueron severamente criticadas por parte de la doctrina: EsTEVE (2013), pp. 4-13.

93 Recurso interpuesto por más de 50 diputados de un grupo parlamentario en el Congreso.

94 STC 31/2018, de 10 abril, FJ 4º: «Como conclusión, el sistema de educación diferenciada es una opción pedagógica que no puede conceptuarse como discriminatoria. Por ello, puede formar parte del derecho del centro privado a establecer su carácter propio».

95 STC 31/2018, de 10 abril, FJ $4^{\circ}$ in fine.
} 
docentes diferentes de los creados por las administraciones públicas son extraordinariamente desiguales dependiendo del lugar de residencia, como los datos estadísticos muestran.

\section{CONClusiones}

Los antecedentes que hemos estudiado señalan que la vida jurídica de la enseñanza privada española sostenida con fondos públicos desde la promulgación de la vigente Constitución de 1978 ha sido accidentada y con abundantes vaivenes. A nuestro juicio, se puede concluir que:

1. El derecho a acceder a financiación pública por parte de los establecimientos docentes privados está reconocido en la Carta Magna española y constituye un derecho de prestación, no solo de libertad. Ahora bien, la configuración de este derecho recae totalmente en el legislador, y no deriva de modo directo e inmediato de la ley fundamental. Asimismo, cabe también señalar que el TC ha dejado un margen muy amplio de apreciación en manos del Parlamento español y en manos de las administraciones educativas de las comunidades autónomas. La descentralización política en España ha deparado un sistema educativo desigual que no es el previsto en la CE.

En efecto, a nuestro juicio, materialmente no hay en España un solo sistema de conciertos educativos, sino varios, en función de las afinidades de las formaciones políticas en el gobierno de cada comunidad autónoma. Esta disparidad de trato no tiene amparo constitucional y lesiona la distribución de competencias diseñada en la Carta Magna, que atribuye al Estado central la competencia exclusiva en la regulación de las condiciones básicas que garanticen la igualdad de todos los españoles en el ejercicio de los derechos (art. 149.1. $1^{\text {a }} \mathrm{CE}$ ), y el desarrollo de la normativa básica del art. $27 \mathrm{CE}$ (art. 149.1. 30ª CE).

2. Hay que concluir, además, que la planificación educativa realizada por las administraciones se ha convertido en el eje de la denegación de peticiones de acceso al concierto educativo. Si se entiende la actividad educativa como un servicio público, las administraciones pueden libremente gestionar si se presta de modo directo o indirectamente través de entes privados. En este trabajo, sin embargo, aducimos las razones constitucionales por las cuales no se debe calificar la educación en general, y la concertada en particular, como servicio público, sino como servicio de interés público, por lo que los centros privados sostenidos con fondos públicos no constituyen una gestión indirecta de un servicio público. Además, defendemos que resulta necesario atender a la demanda social a la hora 
de concertar un centro educativo, esto es, atender a las preferencias contrastadas de madres y padres.

3. A nuestro juicio, en el fondo de toda la controversia late un problema constitucional no bien resuelto. Se trata de la calculada ambigüedad del art. 27 de la CE. En efecto, los artificies del nuevo orden constitucional querían una ley fundamental inclusiva para todos los españoles, que dejase atrás las experiencias constitucionales precedentes, algunas insuficientes y otras sencillamente traumáticas $^{96}$. Esa reconciliación debía empezar por una Constitución de consenso. Y, entre otras, la cuestión educativa no lo tenía, pues los detractores del sostenimiento económico estatal de la enseñanza privada no se avenían a ninguna cesión a este respecto.

La concordia fue posible, pero con un alto precio. En la materia educativa, el reenvío a la posterior legislación de desarrollo debería haber supuesto acuerdos o pactos de Estado que prolongasen el espíritu de acuerdo de la transición ${ }^{97}$. Todo ello, además, requería la lealtad constitucional e institucional de los gobiernos de las nuevas comunidades autónomas.

Una primera lectura de la Constitución puede hacer pensar que, dado que esa legislación requería mayoría absoluta del Parlamento, la necesidad de consenso sería imprescindible. Lamentablemente, esa voluntad de reconciliación de ese momento constituyente, sea de las formaciones políticas de distinta ideología, sea de los nacionalismos periféricos, no se prolongó en el tiempo. Lo cierto es que cuando "los partidos han obtenido mayorías absolutas, en ocasiones las han utilizado para legislar en esta materia sin contar con el concurso de la oposición, o al menos del partido más importante de la oposición98", tanto a nivel estatal como a nivel autonómico.

Este marco constitucional ha deparado 40 años de controversia jurídica, que ha hecho que, en el fondo, el marco jurídico de desarrollo de la libertad de enseñanza, y en especial, de la educación concertada, se haya configurado a "golpe" de sentencias del TC y de los tribunales contencioso-administrativos. Este es uno de los rasgos que caracterizan el modelo español: la jurisprudencia del TC se ha

\footnotetext{
96 Cfr. Álvarez (2005), pp. 429-448.

97 Con el término "Transición Española" se suele denominar el proceso político y constitucional tras la muerte del general Francisco Franco, por el que Juan Carlos I de Borbón fue proclamado rey y dirigió a España hacía una democracia de corte liberal de acuerdo tanto con el régimen autoritario aún vigente como con la oposición democrática a este.

98 VIDAL (2017), p. 13.
} 
convertido en uno de los elementos básicos a la hora de configurar los detalles de este sistema educativo. Y ello ni por voluntad o iniciativa del alto tribunal ni por activismo judicial, sino por el permanente recurso que se ha hecho del Tribunal de Garantías por parte de las formaciones políticas, de las CC. AA. y del propio Estado central. Así pues, se puede afirmar que el TC se ha visto obligado, en ocasiones, a ir más allá de su función de legislador negativo, en un rol que no le corresponde, ante la exasperante falta de consenso de los grupos parlamentarios o ante la neta voluntad del gobierno de algunas CC. AA. de rebasar la Constitución o implementar -de modo ciertamente criticable- una política de hechos consumados, como hemos demostrado en el caso de la discriminación a la que se ha visto sometida la educación diferenciada por sexos.

4. Con todo, por otra parte, esto ha sido un signo de fortaleza de la institucionalidad española, pues, con carácter general, las polémicas se han encauzado a través de los instrumentos que la Carta Magna prevé. Sin atajos alejados del sometimiento a la ley y al derecho de los poderes públicos.

En fin, el ámbito educativo se ha convertido en un termómetro de una de las debilidades de la democracia española, cual es la excesiva politización de todos los aspectos de la vida pública del país. No es buena noticia que la educación, aspecto esencial de toda comunidad política, se haya convertido en campo de batalla y uso partidista en la (legítima) contienda política. Entre muchas razones, porque ello resulta en detrimento de la actividad educativa y, por lo tanto, del derecho fundamental de todo alumno a recibir una enseñanza de calidad 99 .

5. Como conclusión final de este trabajo, a nuestro juicio, urge en España un compromiso político de estabilidad en el ámbito educativo. Como hemos reseñado brevemente con precedencia, está en curso una nueva reforma del sistema educativo, una suerte de contrarreforma de la Lomce, que augura que, de nuevo, los cimientos del sistema volverán a estar en entredicho, continuando en el tiempo la "guerra escolar". Si, de nuevo, se impone una legislación sin consenso, los males que adolece la escuela española se prolongarán en el tiempo... y en los tribunales.

Simultáneamente, se debería dar contenido y competencias a la denominada "Alta Inspección" educativa del Estado, que cuenta con aval competencial en la CE (27.8 CE en relación con el art. 149.1.30a CE). Nuestra propuesta es la creación de una administración independiente, con facultades de inspección, control y sanción, que evalúe y supervise todo el sistema educativo español, emita

99 En palabras de la STC 31/2018, de 10 abril, relativa a la Lomce: «no basta la mera escolarización para atender el derecho a la educación, sino que la calidad es un elemento constituyente de ese derecho». 
informes, y pueda recibir denuncias de madres, padres, profesores y centros docentes de todo el territorio nacional. Ello debe incluir la legitimación activa para interponer recursos contencioso-administrativos contra los actos y reglamentos de las administraciones educativas que repute ilegales o inconstitucionales e incluso la posibilidad de presentar denuncias ante la jurisdicción penal en los casos más graves de prevaricación administrativa ${ }^{100}$. Todo ello, además, con la posibilidad de actuar de oficio o a instancia de interesado.

\section{BIBLIOGRAFÍA CITADA}

Álvarez Tardío, Manuel (2005): El camino a la democracia en España. 1931 y 1978 (Madrid, Editorial Gota a Gota).

BÁEz Serrano, Rafael (2016): "La educación como servicio público en el ordenamiento jurídico español”, en Sánchez Bravo, Álvaro, y Cervi, Jacson Roberto (dirs.), Reflexôes contemporâneas sobre Direitos Humanos, (Santo Ângelo, Fundação Ragional Integrada), pp. 291-312.

Blanquer, David (2013): Los contratos del sector público (Valencia, Editorial Tirant lo Blanch).

Carpintero, Samuel, y Siemiatycki, Matti (2015): "PPP projects in local infrastructure: Evidence from schools in the Madrid region, Spain”, en Public Money \& Management, (Vol. 35, No 6), pp. 439-446.

CAstellà i ANDreu, Josep Maria (2014): "El régimen competencial y las relaciones entre el estado y las Comunidades Autónomas", en Castellà i Andreu, Josep Maria (Ed.), Derecho constitucional básico, (Barcelona, Editorial Huygens, $1^{a}$ edición), pp. 375-396.

Centenera Sánchez-Seco, Fernando (2014): "Educación diferenciada y conciertos educativos: Algunas consideraciones a partir de la jurisprudencia del Tribunal Supremo de los últimos años", en Anuario de Derecho Eclesiástico del Estado (Vol. XXX), pp. 767-796.

Calvo Charro, María (2013): "Los colegios diferenciados por sexo en Estados Unidos: Constitucionalidad y actualidad de una tendencia imparable", en Revista de Derecho Politico, (No 86), pp. 159-194.

$100 \mathrm{El}$ art. 404 del Código Penal español define la prevaricación administrativa como aquel delito en el que incurra: «(...) la autoridad o funcionario público que, a sabiendas de su injusticia, dictare una resolución arbitraria en un asunto administrativo». 
Cotino Hueso, Lorenzo (2014): “El derecho a la educación”, en Noguera Fernández, Albert, y Guamán Hernández, Adoración (Dir.), Lecciones dobre Estado social y derechos sociales (Valencia, Editorial Tirant lo Blanch, 1a edición), pp. 415-450.

De Los Mozos Touya, Isabel (2007): "Programación y libertad escolar: Incidencia en el otorgamiento y denegación de conciertos, aumento y reducción de unidades concertadas", en Cuadernos de Derecho Judicial (No 11), pp. 117-148.

De los Mozos, Isabel (1996): Educación en libertad y concierto escolar (Madrid, Editorial Montecorvo).

De Los Mozos, Isabel (2014): "La Ley Orgánica para la Mejora de la Calidad Educativa: Una reforma contestada, pero de corto alcance", en Revista Española de Pedagogía (No 257), pp. 23-37.

Delvolvé, Pierre (1985): "Le Conseil constitutionnel et la liberté de l'enseignement", en Revue Française de Droit Administratif (No 1), pp. 624-634.

DíAz Lema, José Manuel (2012): Los conciertos educativos en el contexto de nuestro derecho nacional y en el derecho comparado (Madrid, Editorial Marcial Pons, $1^{\text {a }}$ edición).

Díez-Picazo, Luis María (2008): Sistema de derechos fundamentales, $3^{\text {a }}$ edición (Madrid, Thomson-Civitas).

Douence, Jean-Claude (1985): "La porte étroite. Réflexions sur la réforme du systeme éducatif français par la loi du 25 janvier 1985”, en Revue Française de Droit Administratif (No1), pp. 604-623.

Dupont-Marillia, Françoise (2007): L'essentiel des institutions scolaires et universitaires (Paris, Gualino Éditeur).

Durand-Prinborgne (1988): “Le principe d'égalité et l'enseignement", en Revue Française de Droit Administratif (No 4), pp. 584-614.

Embid Irujo, Antonio (1997): "La enseñanza privada en España. Consideraciones sobre su problemática actual en el marco de la política europea sobre educación”, en Revista de Administración Pública (No 142), pp. 75-102.

Esteve PARdo, José (2013): "Paradojas de la discriminación en materia educativa. A propósito de la sentencia del Tribunal Supremo Federal Alemán de 30 de enero de 2013 sobre el modelo de educación diferenciada”, en El Cronista del Estado Social y Democrático de Derecho (No 37), pp. 4-13.

Esteve Pardo, José (2017): Lecciones de derecho administrativo, 7a edición (Madrid, Editorial Marcial Pons). 
Fernández Llera, Roberto; Muñiz Pérez, Manuel (2012): "Colegios concertados y selección de escuela en España: Un círculo vicioso”, en Presupuesto y Gasto Público (No 67), pp. 97-118.

FERnÁNDEZ RodrígueZ, Carmen (2007): “Intervención administrativa y educación para la ciudadanía en la Ley Orgánica de Educación 2/2006”, en Revista de Administración Pública (No 174), pp. 421-455.

FernÁNDEZ-Miranda CAMPOAmor, Alfonso (2006): "El derecho a la educación y la libertad de enseñanza en el mercado educativo”, en De Esteban Villar, Mercedes; Sancho Gargallo, Miguel Ángel; Caballero Sánchez, Rafael; Rodríguez de Santiago, José María (Coord.), Escolarización del alumnado en el sistema educativo español: Cuestiones jurídicas (Valladolid, Fundación Europea Sociedad y Educación, 1a edición), pp. 37-68.

Friedman, Milton (1955): "The Role of Government in Education", en Solo, Robert. (dir.), Economics and the Public Interest, (New Brunswick, Nueva Jersey), pp. 123-144.

Garrido Falla, Fernando (2003): "La elaboración de la Constitución”, en Balado Ruiz-Gallegos, Manuel, y García Regueiro, José Antonio (Dirs.), La Constitución de 1978 en su XXV Aniversario (Barcelona, Editorial Bosch), pp. 231-240. GonzÁlez-VAras IbáN̄eZ, Alejandro (2013): "Régimen jurídico de la educación diferenciada en España”, en Revista General de Derecho Canónico y Derecho Eclesiástico del Estado (No 31).

GonZÁlez-VARAs IbÁÑEZ, Alejandro (2014): "La convivencia escolar y su reflejo en el derecho. Propuestas jurídicas para mejorar el clima en las aulas y la calidad de la enseñanza”, en Revista de Estudios de la Administración Local y Autonómica: Nueva Época, (No 1).

Guardia Hernández, Juan José (2012): “Concesión de uso privativo de suelo de dominio público municipal para un centro docente concertado en la Comunidad Valenciana”, en Práctica Urbanística, (No 116), pp. 12-29.

Guardia Hernández, Juan José (2014): Religió a l'escola catalana. Anàlisi de l'art. 21.2 de l'Estatut d'Autonomia de Catalunya (Cizur Menor, Editorial Thomson Reuters-Aranzadi, $1^{\text {a }}$ edición).

Guardia Hernández, Juan José, y Manent Alonso, Luis (2015): “La cesión de suelo público dotacional para la apertura de centros docentes concertados: Una nueva manifestación del Estado garante", en Revista Catalana de Dret Públic, (No 519), pp. 174-190. 
GurrutXaga, Ander, y Satrústegui, Alfonso (2010): "La función distributiva de la educación: Un análisis aplicado al País Vasco", en Politica y Sociedad, (Vol. 47 No 2), pp. 103-120.

Irureta Uriarte, Pedro (2003): "Las organizaciones de tendencia ante el derecho", en Persona y Sociedad, (Vol. 17, No 2), pp. 235-248.

Manent Alonso, Luis, y Guardia Hernández, Juan José (2016): “El régimen jurídico del plurilingüismo en la enseñanza no universitaria en España”, en Revista de Derecho Político, (No 96), pp. 213-248.

Martínez López-Muñiz, José Luis (2004): "Autonomía de los centros escolares y derecho a la educación en libertad”, en Persona y Derecho, (No 50), pp. 447-448.

Martínez López-MuÑIZ, José Luis (2006a): "El esclarecimiento de la 'constitución educativa'. Un determinante primer paso”, en Persona y Derecho, (No 55), pp. 793-816.

MarTínez López-Muñiz, José Luis (2006b): "Responsabilidad y control administrativo de las libertades en la enseñanza: Introducción”, en De Esteban Villar, Mercedes; Sancho Gargallo, Miguel Ángel; Caballero Sánchez, Rafael; Rodríguez de Santiago, José María (Coord.), Escolarización del alumnado en el sistema educativo español: Cuestiones jurídicas, (Valladolid, Fundación Europea Sociedad y Educación, 1a edición), pp. 109-119.

Martínez López-MuÑIZ, José Luis (2007): "La educación escolar, servicio esencial: Implicaciones jurídico-públicas”, en Cuadernos de Derecho Judicial, (No 11), pp. 15-78.

MARTínez López-MuÑIZ, José Luis (2012): “Escolarización homogénea por razón del sexo y derecho fundamental a la educación en libertad", en Revista Española de Derecho Administrativo, (No 154), pp. 71-108.

Meix Cereceda, Pablo (2013): Descentralización de la enseñanza y derechos fundamentales. Un estudio comparado entre España y Alemania (Madrid, Instituto Nacional de Administración Pública).

Mestre Delgado, Juan Francisco (2009): "La actividad prestacional o de servicio público", en Cano Campos, Tomás (Coord.), Lecciones y materiales para el estudio del derecho administrativo, (Madrid, Editorial Iustel), pp. 121-145.

Ministerio de Educación y Formación Profesional (2018): Datos y cifras. Curso escolar 2018/2019 (Madrid, Secretaría General Técnica. Subdirección General de Atención al Ciudadano, Documentación y Publicaciones).

Monchambert, Sabine (1983): La liberté de l'enseignement (París, Presses Universitaires de France). 
Nuevo López, Pablo (2009): La Constitución educativa del pluralismo. Una aproximación desde la teoría de los derechos fundamentales (Madrid, Universidad Nacional de Educación a Distancia).

Nuevo López, Pablo (2014): "Derechos fundamentales e ideario educativo constitucional", en Revista de Derecho Político (No 89), pp. 205-238.

OtAduy Guerin, Jorge (1986): "Las empresas ideológicas: Aproximación al concepto y supuestos a los que se extiende", en Anuario de Derecho Eclesiástico del Estado, (No 2), pp. 311-332.

Pérez Tremps, Pablo (2013): “Los derechos fundamentales", en López Guerra, Luis (Dir.), Derecho constitucional. El ordenamiento constitucional. Derechos y deberes de los ciudadanos (Valencia, Tirant lo Blanch, 9a edición), pp. 123-149.

Prieto Sanchís. Luis (1978): "Las relaciones Iglesia-Estado a la luz de la nueva Constitución: Problemas fundamentales", en Predieri, Alberto; García de Enterría, Eduardo. (Coord.), La Constitución española de 1978. Estudio sistemático (Madrid, Editorial Civitas), pp. 319-376.

Rivero, Jean (1978): "Décision du 23 novembre 1977 du Conseil Constitutionnel”, en Actualité Juridique Droit Administratif, noviembre, pp. 564-569.

Romea Sebastián, Ángel (2003): Régimen jurídico de los centros concertados (Cizur Menor, Thomson-Reuters-Aranzadi).

Satrustegui, Miguel (2013): "Los derechos en el ámbito educativo”, en López Guerra, Luis (Dir.), Derecho constitucional. El ordenamiento constitucional. Derechos y deberes de los ciudadanos (Valencia, Tirant lo Blanch, 9a edición).

TARdío Pato, José Antonio (2014): "La reforma local española de 2013 y las competencias educativas", en Revista de Educación (No 366), pp. 113-135.

Vidal Prado, Carlos (2017): El derecho a la educación en España. Bases constitucionales para el acuerdo y cuestiones controvertidas (Madrid, Marcial Pons).

\section{NORMAS CITADAS}

Loi No 59-1557 du 31 décembre 1959 sur les rapports entre l'Etat et les établissements d'enseignement privés.

Ley No 14/1970, de 4 de agosto, General de Educación y Financiamiento de la Reforma Educativa.

Ley Orgánica No 8/1985, de 3 de julio, reguladora del Derecho a la Educación. Decreto No 2.377/1985, de 18 de diciembre, por el que se aprueba el Reglamento de Normas Básicas sobre Conciertos Educativos. 
Ley Orgánica No 2/2006, de 3 de mayo, de Educación.

Ley No 17/2007, de 10 de diciembre, de Educación de Andalucía.

Ley No 6/2008, de 26 de diciembre, de Educación de Cantabria.

Ley No 12/2009, de 10 de julio, de Educación de Cataluña.

Ley No 7/2010, de 20 de julio, de Educación de Castilla-La Mancha.

Ley No 4/2011, de 7 de marzo, de Educación de Extremadura.

Real Decreto Legislativo No 3/2011, de 14 de noviembre, por el que se aprueba el Texto Refundido de la Ley de Contratos del Sector Público.

Ley Orgánica No 8/2013, de 9 de diciembre, para la mejora de la calidad educativa. Ley No 6/2014, de 25 de julio, Canaria de Educación no Universitaria.

Real Decreto Ley No 5/2016, de 9 de diciembre, de medidas urgentes para la ampliación del calendario de implantación de la Ley Orgánica No 8/2013, de 9 de diciembre, para la mejora de la calidad educativa.

Ley No 9/2017, de 8 de noviembre, de Contratos del Sector Público.

\section{JURISPRUDENCIA CITADA}

Tribunal Constitucional

Sentencia de 5/1981, de 13 de febrero.

Sentencia de 23/1982, de 13 de mayo.

Sentencia de 30/1985, de 1 de marzo.

Sentencia de 77/1985, de 27 de junio.

Sentencia de 86/1985, de 10 de julio.

Sentencia de 195/1989, de 27 de noviembre.

Sentencia de 15/1990, de 1 de febrero.

Sentencia de 31/2018, de 10 abril.

Tribunal Supremo (Base de datos Wolters Kluwer)

Sentencia de 27 de septiembre de 2004 (CJ 2164/2004).

Sentencia de 1 de febrero de 2005 (CJ 11163/2005).

Sentencia de 26 de junio de 2006, recurso de casación No 3.356/2000.

Sentencia de 30 de enero de 2007 (CJ 2471/2007).

Sentencia de 21 de mayo de 2007 (CJ 26869/2007).

Sentencia de 16 de abril de 2008, recurso de casación No 675/2005.

Sentencia de 11 de julio de 2008, recurso de casación No 689/2005.

Sentencia de 18 de julio de 2008 (CJ 96612/2008). 
Sentencia de 22 de julio de 2008 (CJ 112761/2008).

Sentencia de 23 de julio de 2012 (CJ 110633/2012).

Sentencia de 24 de julio de 2012 (CJ 110636/2012).

FRANCIA

Decisión del Consejo de Estado francés de 25 de abril de 1980.

Decisión No 84-185, del Consejo Constitucional francés de 18 de enero de 1985. 
